\title{
Candidate Ideology and Vote Choice in the 2020 US Presidential Election*
}

\author{
David E. Broockman ${ }^{\dagger} \quad$ Joshua L. Kalla
}

May 4, 2021

\begin{abstract}
A prominent literature argues that moderate candidates perform better in general elections, but a competing literature that emphasizes voters' partisan loyalties contests these predictions. The 2020 Democratic Presidential primary represented an opportunity to speak to these debates due to relatively high voter information about multiple moderate and extreme candidates running in the same election. We present results from both an existing ( $n=62,275)$ and an original $(n=12,725)$ national survey that asked how respondents would choose in a general election between one of the Democratic candidates and Republican Donald Trump. Our evidence is consistent with moderates having an electoral advantage: more moderate Democratic candidates receive more support against Trump than do more extreme Democratic candidates. Republican partisans contribute to Democratic moderates' advantage: $\approx 2 \%$ select Trump against a more extreme Democrat but not against a more moderate Democrat. One of the more extreme candidates, Bernie Sanders, ostensibly deviates from this pattern, but only under unlikely assumptions about turnout. Our point estimates are larger than Biden's margin of victory in pivotal states in the 2020 general election. Our findings lend further support to the hypothesis that moderate candidates are electorally advantaged.
\end{abstract}

\footnotetext{
*We thank the Silicon Valley Community Foundation for supporting this research. We thank Peter Aronow, Alex Coppock, Donald Green, Anthony Fowler, Justin Grimmer, Dan Hopkins, Gabriel Lenz, Jonathan Robinson, Brian Schaffner, Eric Schickler, Jas Sekhon, Aaron Strauss, Rob Van Houweling, and Lynn Vavreck for helpful feedback. The authors disclose that they have previously made personal contributions to the presidential campaigns of Sanders, Warren, Buttigieg, Klobuchar, and Castro.

${ }^{\dagger}$ Associate Professor, Political Science, University of California, Berkeley. dbroockman@berkeley.edu. https://polisci.berkeley.edu/people/person/david-broockman

Assistant Professor, Department of Political Science and Department of Statistics and Data Science, Yale University. josh.kalla@yale.edu, https://joshuakalla.com
} 
A prominent perspective in the American politics literature argues that more moderate candidates on average perform better than more extreme candidates in general elections (e.g., Ansolabehere, Snyder and Stewart 2001; Canes-Wrone, Brady and Cogan 2002; Hall 2015; Hall and Thompson 2018; Hill 2017). For example, Canes-Wrone, Brady and Cogan (2002, p. 133) find that Members of Congress who cast 3 to 4 additional high-profile votes aligned with the extreme of their party receive 1 to 3 percentage points fewer votes in the next election 11 However, skepticism of whether electorates reward candidates with more moderate platforms remains. Much of this skepticism comes from the behavioral literature in American politics, which emphasizes the strength of voters' loyalties to their own party and their stated disdain for the other, arguing partisanship overrides other considerations such as candidates' policy positions (e.g., Campbell et al. 1960; Lenz 2012; Achen and Bartels 2016). In a recent review and critique, Fowler et al. (2020) summarizes this literature as arguing that voters exhibit "partisan intoxication."

In this paper, we speak to this debate on the relationship between ideological extremity and electoral performance with data collected during the 2020 Democratic Presidential primary. We analyze two large survey datasets that asked how respondents would vote in a general election between Republican Donald Trump and one of the candidates for the Democratic nomination. We examine choices between Trump and five of the candidates who were the most plausible nominees during the most highly publicized part of the primary, the first few months of 2020. These five candidates included three generally perceived as more moderate both by respondents to our survey and by political observers more generally: Joe Biden, Michael Bloomberg, and Pete Buttigieg. There were also two candidates seen as more extreme by both respondents to our survey and political observers: Bernie Sanders and Elizabeth Warren. ${ }^{2}$

\footnotetext{
1 Abramowitz (2019) likewise finds that Democratic vote margin was approximately 4.6 percentage points lower in the 2018 US House elections in districts where the Democratic nominee supported Medicare For All.

${ }^{2}$ When our original survey launched (January 21, 2020), these five candidates were far ahead of the remaining candidates in national polling averages of vote intentions in the Democratic primary. Table A1 reports the national polling average as of that date. The two candidates with the next most support were Amy Klobuchar and Andrew
} 
We should not expect evidence from any one election to provide dispositive evidence regarding an enduring debate in political science on the role of ideology in general elections. However, data from the case we consider can crucially inform this debate, as it complements prior empirical work on candidate ideology and vote choice in several ways:

- We are able to conduct comparisons across candidates while holding constant the electoral context. As Hall (2015) discusses, research on candidate ideology faces the challenge that extreme candidates may run in different kinds of elections than moderate candidates (e.g., in different districts or at different times), confounding comparisons between moderate and extreme candidates' electoral performance. However, as few other studies are able (e.g., Hall 2015; Hall and Thompson 2018), this case allows us to hold constant the electoral context because all of the candidates we examine ran in the same election.

- We are able to examine the case of presidential elections, whereas most existing work on candidate ideology and electoral performance focuses on legislative elections, such as for US House. Due to the small number of presidential elections in US history, candidate ideology in presidential elections has received relatively less attention in prior empirical research (e.g., Cohen et al. 2016).

- The 2020 Democratic Presidential primary featured a relatively large number of candidates whom voters widely understood to be more extreme or more moderate. That is, a) there was meaningful variation in candidate ideology among candidates for the 2020 Democratic Presidential nomination; b) as we show below, voters appeared to perceive this variation; and, c) helping reduce concern that our conclusions may be idiosyncratic to a particular candidate, there were multiple more moderate and multiple more extreme candidates that were diverse along many other dimensions that could plausibly be relevant to voters (e.g., age, gender, region, sexual orientation, prior experience).

Yang, who as of that date received significantly less support than the five candidates we include. 
- The large sample of individual-level survey data we analyze allows us to determine which types of individuals are responsible for the aggregate differences we observe (i.e., to examine treatment effect heterogeneity by individual voter attributes) more precisely than smaller survey-based studies or in studies with only aggregate outcomes.

- However, unlike much other survey-based research, we are able to examine how voters say they would choose between real candidates in a real election, not hypothetical candidates in a hypothetical election (McDonald 2020).

All research on candidate ideology and electoral success has weaknesses, and there are several weaknesses of our research design that should be kept in mind:

- Most obviously, our results come from one set of candidates in one election. Although rigorous studies of variation within a particular case can be informative (Fowler 2013; Lo et al. 2013), conclusions from the 2020 election may not generalize to other elections.

- As survey responses are ill-suited to measuring turnout decisions (Rogers and Aida 2014), our data is not well-suited to capturing any effects on turnout from nominating extreme candidates, such as extreme candidates inspiring turnout among outpartisans (Hall and Thompson 2018; Hill 2017). We therefore consider how different assumptions about turnout could alter our conclusions.

- Survey responses capture stated preferences that may not correspond with real behavior, such as if respondents answer expressively or strategically (Bullock et al. 2015). For example, as we document below, a meaningful percentage of Sanders supporters report they would abstain from the general election if a more moderate candidate were the Democratic nominee. We cannot be certain the extent to which this is genuine, strategic, or expressive responding, and so we examine the robustness of our conclusions to different approaches to forecasting the likely electorate. 
- Our survey took place before a Democratic nominee was selected and well before the general election took place. As a result, the media, voters, opposing campaigns, etc. had not yet reacted as they might were each candidate actually nominated, such as by better informing the electorate about the Democratic nominee's flaws. That is, our results are more appropriately thought of as capturing voters' partial equilibrium response to candidate ideology among voters who were aware of these differences early on in the election cycle, a question relevant to but distinct from how entire electorates respond to candidate ideology in general equilibrium when the general election takes place.

With these caveats in mind, our findings nevertheless provide further evidence consistent with the prediction that moderate candidates enjoy electoral advantages. Examining respondents' choices, respondents are significantly more likely to vote for Donald Trump instead of the Democratic candidate in a general election matchup with an extreme Democratic candidate than with a moderate Democrat. Contrary to the expectations from the behavioral literature that partisans are too loyal to their parties to reward moderation from the other party's candidates (e.g., Achen and Bartels 2016), we find that Republican partisans significantly contribute to moderate Democratic candidates' superior performance against Trump: $\approx 2 \%$ of Republicans in our survey answer as if they would vote for Trump if a more extreme Democrat were nominated but would vote for the Democratic candidate were a more moderate Democrat nominated. While Hall and Thompson (2018) find that extremist nominees fare worse in congressional general elections through a mobilization mechanism, these results suggest that in presidential elections, a persuasion or vote-switching mechanism may also operate (Hill, Hopkins and Huber 2021).

\section{Data and Methods}

We present data from two large surveys, summarized in Table 1 . Both surveys asked respondents how they would choose between Donald Trump and one or more of the Democratic candidates in 
a general election. The large sample size of these surveys allow us to detect shifts in candidate choices across Democratic candidates that, while small in absolute terms, could be electorally consequential.

Table 1: Samples Used in Analysis

\begin{tabular}{|c|c|c|}
\hline Dataset & Nationscape & Original Data \\
\hline $\mathbf{N}$ & 62,275 (in eligible time period) & 12,725 \\
\hline Dates & January 23 - April 1, 2020 & January 21 - February 24, 2020 \\
\hline $\begin{array}{l}\text { Candidates } \\
\text { Examined }\end{array}$ & \multicolumn{2}{|c|}{ Biden, Bloomberg, Buttigieg, Sanders, Warren } \\
\hline Design & $\begin{array}{l}\text { Within-Subject (All Respondents } \\
\text { Shown All Candidates Still In } \\
\text { Race As Of Survey Date) }\end{array}$ & $\begin{array}{l}\text { Between-Subject (Respondents Shown } \\
\text { Only One Candidate) }\end{array}$ \\
\hline $\begin{array}{l}\text { Response } \\
\text { Options }\end{array}$ & $\begin{array}{l}\text { (1) Trump, (2) Democratic } \\
\text { Candidate, (3) Don't Know }\end{array}$ & $\begin{array}{l}\text { (1) Trump, (2) Democratic Candidate; } \\
\text { Other Selections Asked Follow-up with } \\
\text { Options: Candidates, (3) Completely } \\
\text { Undecided, (4) I Definitely Would Not } \\
\text { Vote (Would Not Vote In Second Round } \\
\text { of Data Collection Only) }\end{array}$ \\
\hline Weights & $\begin{array}{l}\text { Provided by Nationscape, General } \\
\text { Population Target (2017 ACS and } \\
2016 \text { Presidential Vote) }\end{array}$ & $\begin{array}{l}\text { Computed: ACS (general population), } \\
\text { Likely Electorate (various methods) }\end{array}$ \\
\hline
\end{tabular}

\section{Nationscape Survey}

The first survey dataset we analyze is from the publicly available Nationscape project, a large survey sample collected by UCLA and the Democracy Fund (Tausanovtich et al. 2019). Beginning in July 2019, the Nationscape project interviewed thousands of respondents every week using the survey platform Lucid. The project makes available detailed information regarding the representativeness of its samples ${ }^{3}$

The Nationscape surveys contained a large number of questions about a variety of political ${ }^{3}$ See https://www.voterstudygroup.org/uploads/reports/Data/NS-Methodology-Representativeness-Assessment.
pdf. 
topics (for further details, see Tausanovtich et al. 2019). Among them, many waves of the Nationscape survey contained questions like the following:

If the general election for president of the United States was a contest between [DEMOCRATIC CANDIDATE] and Donald Trump, who would you support?

\section{- [DEMOCRATIC CANDIDATE]}

- Donald Trump

- Don't Know

There were no follow-up questions for respondents who said they did not know how they would vote.

Each respondent was asked about several Democratic candidates. E.g., the same respondents were asked how they would vote between Joe Biden and Donald Trump and between Bernie Sanders and Donald Trump. The order of the candidates were randomized for each respondent.

We use data starting in Nationscape's 28th survey wave, which began on January 23, 2020, the week before the Iowa caucus. We selected this cutoff date because it coincides with the beginning of our second survey sample, making the two more comparable, and because it means the data covers the period of the campaign when there was the most media coverage of the candidates. We use the data until the survey's 37th wave, which ended April 1, 2020, the week before Bernie Sanders dropped out of the race, when Biden became the presumptive nominee.

Nationscape only asked respondents how they would choose between Trump and Democratic candidates who had not yet dropped out as of the day of the survey, so all the responses describe candidates still in the race of the survey date..$^{4}$

\footnotetext{
${ }^{4}$ Our specifications include respondent fixed effects, and each respondent only appears in the dataset at one particular time, so our specification does not confound differences between candidates with differences across time, as all of our comparisons are conducted within a given time period (as they are within-respondent). Two waves of the Nationscape survey asked how respondents would choose between Trump and Michael Bloomberg after Bloomberg had dropped out, so we remove the observations for Bloomberg on these dates.
} 
Our analyses use the survey weights provided in the Nationscape data. The Nationscape project computed these weights using the 2017 ACS as well as several other variables, such as 2016 Presidential vote and the urban-rural mix of the respondent's home zip code.

To match our original survey (described below) and to focus only on candidates with a plausible chance of winning the nomination as of the survey dates, we focus on how respondents chose between Trump and five of the candidates: Biden, Bloomberg, Buttigieg, Sanders, and Warren. These five candidates were the leading contenders for the Democratic nomination as of early 2020; as Table A1 shows, they were far ahead of the remaining Democratic candidates in national polling during this period.

\section{Original Surveys}

We also analyze a dataset of original surveys we collected. As part of surveys for other projects $5^{5}$ we collected 12,725 unique survey responses during January 21 - February 24, 2020. We collected the responses using the online platform Lucid, which is the same data vendor the Nationscape project used and which Coppock and McClellan (2019) validate as relatively nationally representative. 6

In these surveys, we asked respondents how they would choose in a contest between Donald Trump and one of the five Democratic candidates named above: Bernie Sanders, Elizabeth Warren, Joe Biden, Michael Bloomberg, and Pete Buttigieg. Note that, unlike in the Nationscape survey, in our original survey each respondent was only asked about how they would choose between Trump and one Democratic candidate. We intended for this to reduce strategic

\footnotetext{
${ }^{5}$ In Broockman and Kalla (2020), we analyze the effects of campaign messages. For that project, some respondents were shown attacks on the Democratic candidates. We remove those respondents from the data we analyze in this paper. Separately, in Kalla and Broockman (2020), we analyze the effect of perspective taking on reducing exclusionary attitudes. The perspective taking material was at the end of the survey, after all data we present in this project had been collected.

${ }^{6}$ This encompasses two separate rounds of surveying. A first round was conducted from January 21 to February 9 and the second round from February 9 to February 24. We describe a small difference in question wording between the two rounds below.
} 
responding, as individual respondents did not have the opportunity to indicate that they would vote for the Democratic candidate only if their preferred candidate was nominated but not if another was.

Our surveys began by asking respondents for their informed consent and ensuring that they were paying attention $]^{7}$ After dropping respondents who did not consent or who did not pass attention checks, 12,725 remained, approximately 2,500 observations per candidate.

Next, we asked a series of demographic and baseline political questions. Respondents then read a brief preamble about the upcoming election and we randomly assigned them to one of the five Democratic candidates. Finally, we asked respondents how they would vote in a contest between Republican Donald Trump and their randomly selected Democratic candidate. If respondents said they were unsure or preferred a third party, we asked them in a branching question if they leaned towards Trump, leaned towards the Democrat, or were completely undecided.

Appendix $\mathrm{B}$ gives the full question wordings.

During the second half of the survey field period surveying (see Footnote 6), we added a "would not vote" option to our survey question measuring 2020 presidential vote choice. While survey responses are not a reliable predictor of actual turnout (Rogers and Aida 2014), this option helps us interpret what respondents meant when they said they did not know how they would choose between the candidates (i.e., if they were genuinely undecided, if they planned to vote third party, or if they thought they would not vote).

To assess the robustness of our results, we compute multiple sets of survey weights in our original survey data. Our first set of weights uses the general population as the target, computed

\footnotetext{
${ }^{7}$ In particular, after providing consent, the first question asked: "For our research, careful attention to survey questions is critical! We thank you for your care." Respondents were shown "I understand" and "I do not understand" in a randomized order. If a respondent did not select "I understand", they were removed from the survey. Similarly, the second question asked: "People are very busy these days and many do not have time to follow what goes on in the government. We are testing whether people read questions. To show that you've read this much, answer both 'extremely interested' and "very interested." Respondents were shown "Extremely interested", "Very interested", "Moderately interested", "Slightly interested", and "Not interested at all". If a respondent did not select both "Extremely interested" and "Very interested" and nothing else, they were removed from the survey. 20\% of subjects were dropped because they failed these attention checks.
} 
using the US Census' 2018 5-Year Estimates American Community Survey (ACS). We constructed weights using age, gender, household income, ethnicity/race, education among Whites $]^{8}$ and region 9 We also compute a second and third set of weights that weight to the demographics of the 2016 electorate, as computed from the 2016 Cooperative Congressional Election Study's (CCES) (Ansolabehere and Schaffner 2017) validated voting information. We compute the second set of weights from the 2016 CCES using age, gender, household income, ethnicity/race, and education among Whites $^{10}$ and a third, more expanded set using 2016 presidential vote choice, race-by-education interactions, race-by-age interactions, gender, and household income 11 A fourth set of weights checks the robustness of our findings when using estimates of the demographic composition of the 2016 electorate from Catalist, a political data vendor that maintains a national voter file, instead of the CCES. Here we weight on gender, age, ethnicity/race, and education among Whites ${ }^{12}$ Motivated by concerns that Trump's presidency may have altered turnout patterns, a final set of weights similarly checks for the robustness of our findings by weighting to the demographics of the 2008 and 2012 electorates computed using data

\footnotetext{
${ }^{8} \mathrm{We}$ limit education weighting only to White respondents because the education gap in political views is most pronounced among Whites. See https://www.people-press.org/2018/03/20/wide-gender-gap-growing-educational-d ivide-in-voters-party-identification/.

${ }^{9} \mathrm{Age}$ bins: $18-24 ; 25-44 ; 45-64 ; 65$ and older. Household income: under $\$ 15,000 ; \$ 15-20,000 ; \$ 20-25,000$; $\$ 25-$ 30,000; \$30-35,000; \$35-40,000; \$40-45,000; \$45-50,000; \$50-60,000; \$60-75,000; \$75-100,000; \$100-125,000; $\$ 125-150,000 ; \$ 150-200,000 ; \$ 200,000$ and over. If a respondent chose prefer not to say, we imputed a household income of \$55,000. Ethnicity/race: African-American; Hispanic; Asian; Native American; Other. Education among Whites: White some high school or less; White high school graduate; White other post high school vocational training; White completed some college; White Associate's degree; White Bachelor's degree; White Graduate degree. If a respondent chose prefer not to say, we imputed an education level of completed some college. Region: Northeast; Midwest; South; West. Gender: male; female.

${ }^{10}$ Age bins: $18-24 ; 25-34 ; 35-44 ; 45-64 ; 65$ and older. Household income: under \$20,000; \$20-30,000; $\$ 30-40,000 ; \$ 40-50,000 ; \$ 50-60,000 ; \$ 60-70,000 ; \$ 70-80,000 ; \$ 80-100,000 ; \$ 100-150,000 ; \$ 150-200,000 ; \$ 200-$ 250,000; $\$ 250,000$ and over; prefer not to say. Ethnicity/race: African-American; Hispanic; Asian; Native American; Other. Education among Whites: White some high school or less; White high school graduate; White completed some college; White Associate's degree; White Bachelor's degree; White Graduate degree. Gender: male; female.

${ }^{11} 2016$ presidential vote choice: Clinton, Trump. Race/Education: White, Black, Hispanic, Asian interacted with some high school or less, high school graduate, completed some college, Associate's degree, Bachelor's degree, Graduate degree. Race/Age: White, Black, Hispanic, Asian interacted with 18-24, 25-34, 35-44, 45-64, 65 and older. Household income: under $\$ 20,000$; \$20-30,000; $\$ 30-40,000$; $\$ 40-50,000$; \$50-60,000; $\$ 60-70,000 ; \$ 70-80,000$; $\$ 80$ 100,000; \$100-150,000; \$150-200,000; \$200-250,000; \$250,000 and over; prefer not to say. Gender: male; female.

${ }^{12}$ Age bin: 18-29; 30-39; 40-49; 50-64; 65 and older. Ethnicity/race: African-American; Hispanic; Other. Education among Whites: White without college degree; White with college degree. Gender: male; female.
} 
from Catalist and the CCES. All survey weights are constructed using data from both rounds of surveys with entropy balancing (Hainmueller 2012).

\section{Statistical Models}

To analyze the Nationscape data, we stack the data at the respondent-by-candidate level and run regressions like the following:

$$
y_{i, j}=\beta_{j} J_{j}+\gamma_{i}+\alpha+\epsilon_{i}
$$

in which we predict how respondent $i$ said they would vote between Donald Trump and Democratic candidate $j . \beta_{j}$ is a vector of coefficients of interest for each Democratic candidate $j$ (with one candidate's coefficient omitted as the omitted category), and $J$ is a vector of candidate indicators (with one candidate omitted as the omitted category). In some specifications we pool the candidates we code as moderate and not-moderate, replacing $J_{j}$ with an indicator for whether a candidate is moderate or is not, depending on the analysis. $\gamma$ is a vector of fixed effects for individual respondents, so all of our comparisons are within-respondent for the Nationscape data. $\alpha$ is the intercept term. We cluster the standard errors at the respondent level.

$y$ is coded as -1 if the respondent indicated that they would support towards Donald Trump; 0 for "don't know"; and 1 if supporting the Democratic candidate. This coding of the dependent variable allows for a straightforward comparison of the differences in expected vote margins against Trump between the different Democratic candidates.

In our original survey data, we use a similar statistical model, although because we only asked about one candidate per respondent, there is only one observation per respondent. Accordingly, in our original survey data, we run regressions like the following:

$$
y_{i}=\beta_{j} J_{j}+\gamma X_{i}+\alpha+\epsilon_{i}
$$


in which we predict how respondent $i$ said they would vote between Donand Trump and Democratic candidate $j . \beta_{j}$ is a vector of coefficients of interest for each Democratic candidate (again with one candidate's coefficient omitted as the omitted category). In some specifications we pool the candidates we code as moderate and not-moderate, replacing $J_{j}$ with an indicator for whether a candidate is moderate or is not, depending on the analysis. Because we randomized which Democratic candidate each respondent was asked about, we can assess the relative performance of each potential Democratic nominee among statistically exchangeable respondents.

$X_{i}$ is a vector of controls based on pre-treatment survey questions we use to increase the precision of these between-subject comparisons ${ }^{13} \alpha$ is the intercept term. We use robust standard errors.

The dependent variable $y$ is coded in the same manner as in the Nationscape surveys, although we incorporate our second question asked of those who said they initially did not know who they would vote for as follows: the -1 and 1 categories include respondents who said they leaned towards one of candidates, and those who said they were completely undecided or would not vote are assigned 0.

\section{Results}

\section{Perceptions of Candidate Ideology}

First, we verify that respondents perceive the expected ideological differences between the candidates. We asked respondents at the end of our survey to place the major candidates and Trump on a 7-point ideological scale. Figure 1 shows that respondents place Bloomberg, Biden,

\footnotetext{
${ }^{13}$ These controls are for region, political party, ethnicity, education, age, gender, household income, ideology, generic US House vote choice, 2016 presidential vote choice, a measure of current US economic conditions, a measure of expected US economic conditions, a measure of personal finances, an index of four measures of rightwing authoritarianism, and favorability towards Trump, Congress, and the police.
} 
and Buttigieg at more moderate positions on the scale than Warren and Sanders. Moreover, voter knowledge about the candidates' ideology appeared relatively high; on average, $23 \%$ of voters said they did not know how to ideologically place the Democratic candidates, only slightly higher than the $15 \%$ of voters who said they did not know how to place Trump ideologically. Among those placing Trump on the ideological scale, $78 \%$ say he is conservative.

Figure 1: Placements of Trump and Democratic Candidates on Left-Right Ideological Scale

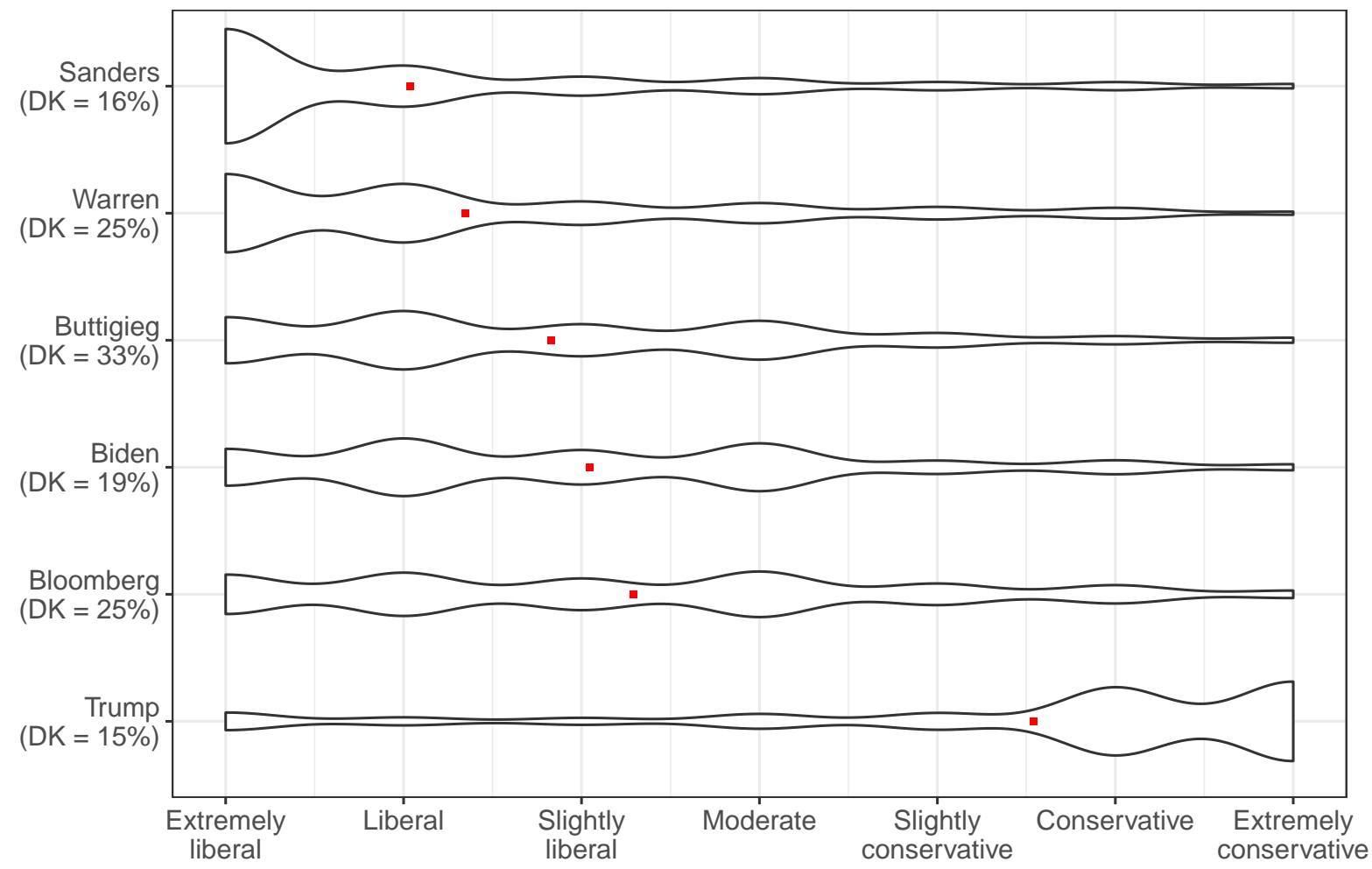

Note: Each plot shows the distribution of responses to the ideological placement question by candidate. The red square is the mean, calculated excluding respondents who did not know. Below each candidate's name is the percentage of respondents who did not know how to place the candidate on the ideological scale. These estimates are weighted using the General Population (ACS). Figure A1 shows the results by respondent party and Table A2 shows pairwise comparisons of the candidates.

These levels of ideological knowledge are fairly comparable to other publicly available polling from this time. For example, the 2019 CCES asked respondents to rate the ideology of Donald Trump. $21 \%$ of respondents answered "Not sure" and $82 \%$ of respondents who placed Trump on 
the ideological scale said he is conservative. Similarly, according to YouGov polling from January and February 2020, around 20\% of respondents answered "Not sure" for Trump's ideology and $75 \%$ considered him to be conservative 14

\section{Voter Support by Candidate}

Next, we examine the differences in expected vote margins for Donald Trump when he is against different Democratic candidates (the $\beta$ coefficients in the models above).

The first row in Figure $2 \mathrm{a}$ reports the results of a regression where we compare all moderate candidates (Biden, Bloomberg, Buttigieg) to all non-moderates (Sanders and Warren), using Equation 1. As described above, we use Nationscape's provided weights. We find a statistically significant increase in Democratic vote margin when comparing the performance of all moderate candidates to all non-moderate candidates, with moderates performing better by $\beta=0.0088$, or 0.88 percentage points $(S E=0.0028, t=3.16)$.

The remaining rows of Figure $2 \mathrm{a}$ report coefficients from a second regression, again following Equation 1, where we make Joe Biden the baseline category and compare Biden's performance against the performance of the remaining candidates. As can be seen, Biden performs significantly better against Trump than both Bernie Sanders $(\beta=-0.0089, S E=0.0035, t=-2.57)$ and Elizabeth Warren $(\beta=-0.0517, S E=0.004, t=-12.23)$. Both Michael Bloomberg and Pete Buttigieg also appear to do worse than Biden, although in the case of Bloomberg the difference is not statistically significant. Overall, then, Figure $2 \mathrm{a}$ shows that moderates perform better than extremists on average, with eventual nominee Biden performing better than both extremists but with some heterogeneity among the candidates.

Figure $2 \mathrm{~b}$ reports the results of these same analyses but in our original survey data. Recall that our original survey data only asked each respondent about how they would vote between one of the candidates and Trump, and so we only have between-subject data. The sample size of

\footnotetext{
${ }^{14} \mathrm{See}$ https://today.yougov.com/topics/politics/trackers/donald-trumps-ideology.
} 
Figure 2: Vote Choice - Entire Sample

(a) Nationscape

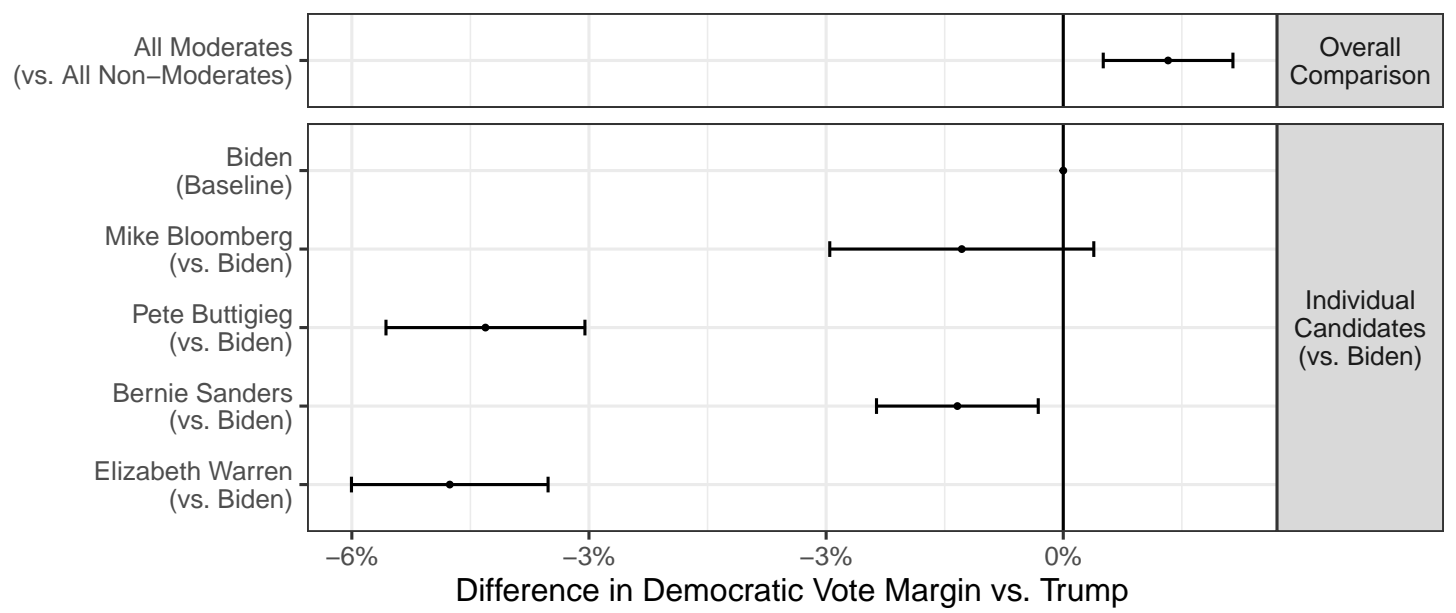

Notes: Point estimates are $\beta$ coefficients from the regression given in Equation $1.95 \%$ confidence intervals surround point estimates. The first coefficient reports the $\beta$ from one regression, the remaining coefficient reports the $\beta$ parameters from a second regression. All regressions use Nationscape's included weights. The regression results from which the coefficients reported in this Figure are drawn are reported in Table A4.

(b) Original Survey

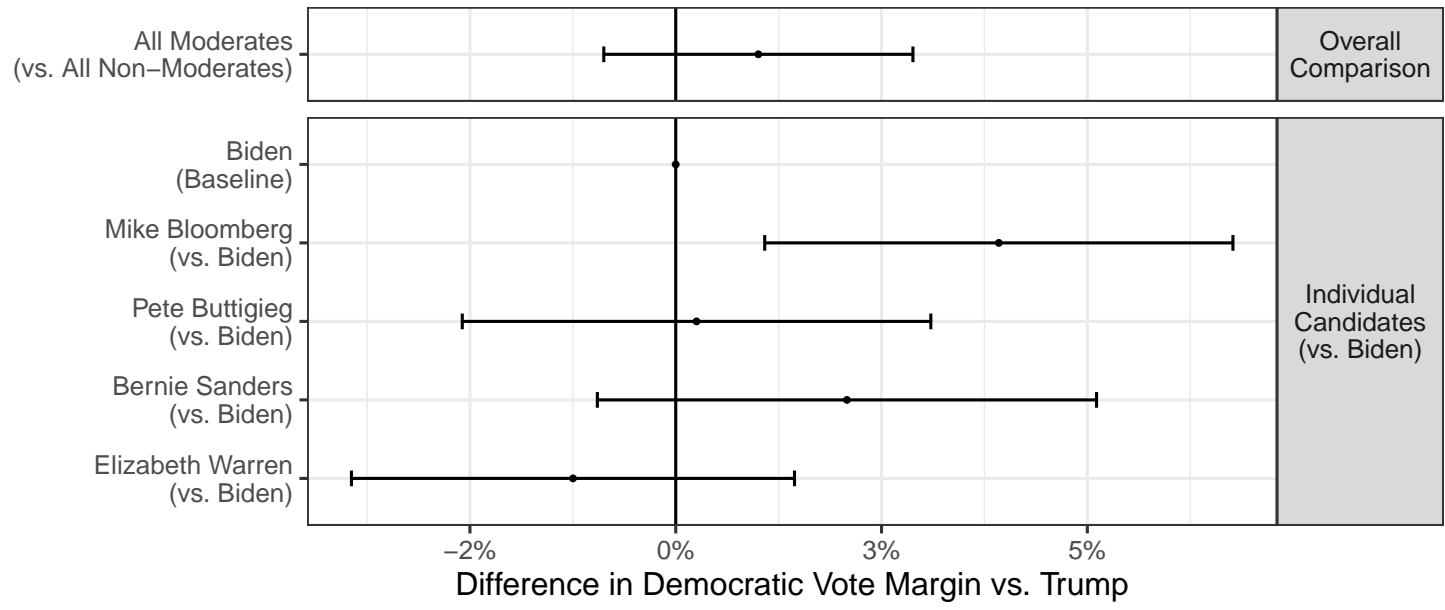

Notes: Point estimates are $\beta$ coefficients from the regression given in Equation 2. 95\% confidence intervals surround point estimates. The first coefficient reports the $\beta$ from one regression, the remaining coefficient reports the $\beta$ parameters from a second regression. This Figure uses General Population (ACS) weights. The regression results from which the coefficients reported in this Figure are drawn are reported in Table A5. 
our original survey is also smaller. This makes our standard errors larger. Nevertheless, we see qualitatively similar results. Overall, our first regression results shows that we again estimate that the moderates would do better than the extremists. Although it falls short of statistical significance, the result in our original survey is similar in magnitude to the estimate from the Nationscape survey $(\beta=0.0100, S E=0.0096, t=1.05)$.

The remaining coefficients again compare Biden's performance to the performance of the other candidates. The results are qualitatively similar to the Nationscape data, but noisier. One important difference is that the point estimate for Bernie Sanders, which was significant and negative in the Nationscape data, is now slightly positive in our original data, although not significantly so $(\beta=0.02080, S E=0.0155, t=1.34)$.

In the remainder of the paper, we examine the data more closely in two ways, reaching two additional conclusions.

First, we examine what drives the overall superior performance of moderates. We find that moderates' support is driven by Republican voters who say they would cross party lines to vote for a moderate Democrat but who would otherwise vote for Trump against a more extreme Democratic nominee.

Second, as part of this examination, we show that Sanders' relatively strong position appears to arise because many young Democrats and Independents claimed they will not vote unless Sanders was the nominee. We show that this is responsible for Sanders' ostensibly strong performance and that reasonable corrections for likely turnout diminish Sanders' performance.

\section{Understanding Moderates' Sources of Support}

The Democratic vote margin outcome analyzed in Figure 2 relied on a trichotomous outcome ( $y$ from Equations 1 and 2) defined as -1 if individuals said they would vote for Trump, 1 if they said they would vote for the Democratic candidate in the match-up, and 0 otherwise (in Nationscape, this is "Don't know", in our survey this is "Completely undecided" or "I definitely would not vote" 
(in the second round of data collection only)).

In this section we examine which of these three categories drives changes in vote margin for moderates versus for Sanders and among what subgroups. Here, we focus on comparing the moderates' performance to Sanders' only, and not to Warren's, because Sanders' position remains somewhat ambiguous from Figure 2 but Warren's is consistently the lowest performing candidate. This examination helps bolster confidence that moderates win votes that extremist candidates do not.

Figure 3 shows the difference between the share of the vote that goes to the Trump, Don't know or Neither/Would not vote, and Democratic nominee categories when a moderate instead of Sanders is the nominee in the match-up. In particular, each coefficient in Figure 3 reports the results of a separate regression conducted among the subgroup shown on the left, where we define the outcome $y$ as a dichotomous variable equal to 1 if the respondent selected the category at the top of the graph and 0 otherwise. $\beta$ then captures the effect of nominating one of the three moderates instead of Sanders. These regressions all use ACS weights and the specifications described in Equations 1 and 2. For instance, the top-most and left-most coefficient in Figure $3 \mathrm{a}$ shows that, in a regression in the Nationscape sample, Republican respondents are 2 percentage points more likely to say they would vote for Trump if Sanders is the nominee in the match-up than if a moderate is the nominee in the match-up.

Moderates' advantage over Sanders is driven by Republicans being more likely to say they would vote for Trump, and less likely to say they would vote for the Democratic candidate, if Sanders is the nominee. The top rows of Figures $3 a$ and $3 b$ show that these results appear in both datasets. In the Nationscape data, Republicans are 2.0 percentage points more likely to say they would vote for Trump if Sanders is the nominee instead of one of the moderates $(S E=$ $0.0028, t=7.40$ ), and 1.0 percentage points less likely to say they would vote Democratic if Sanders were the nominee $(S E=0.0025, t=-3.81)$. In our original survey data, the estimates are substantially noisier but similar in magnitude: Republicans are 1.9 percentage points more 
Figure 3: Vote Choice by Party: Sanders' Nomination Increases Votes for Trump, Decreases Votes for Democrats Among Republicans Relative to More Moderate Democrats

(a) Nationscape

\section{Vote Gains from Nominating Sanders Rather Than Moderate}

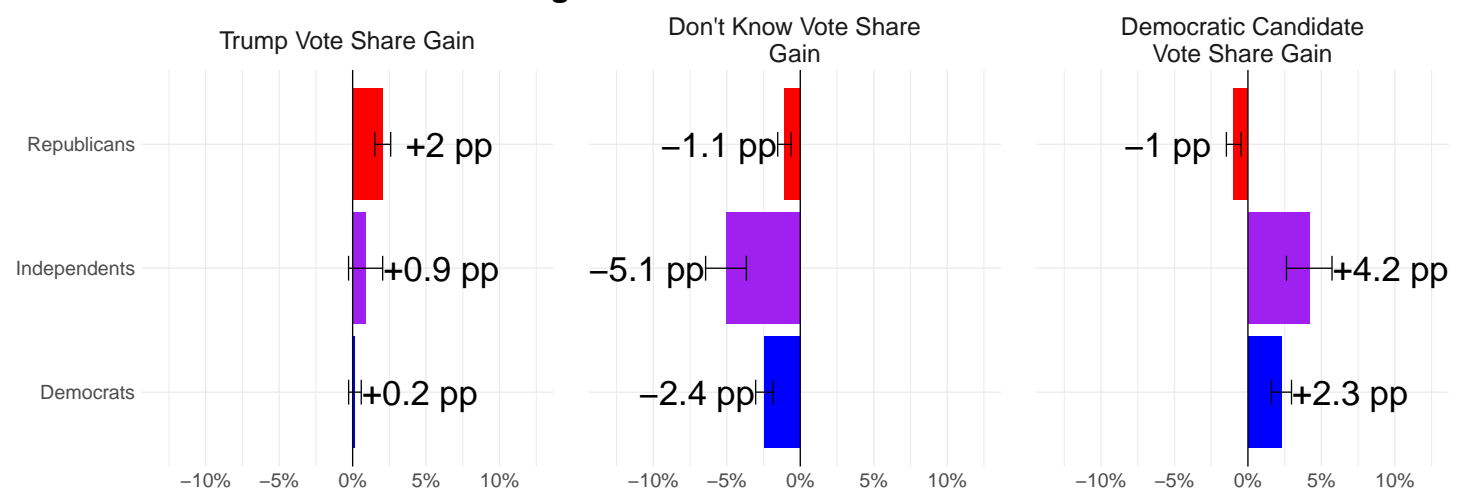

Notes: Each coefficient is from a separate regression conducted among the subgroup shown at left and where the dependent variable is 1 if the respondent selected the category shown at top and 0 otherwise. All regressions use the Nationscape included weights. The regressions otherwise are identical to that shown in $1795 \%$ confidence intervals surround point estimates. All regressions use Nationscape's included weights. The regression results from which the coefficients reported in this Figure are drawn are reported in Table A6.

(b) Original Survey

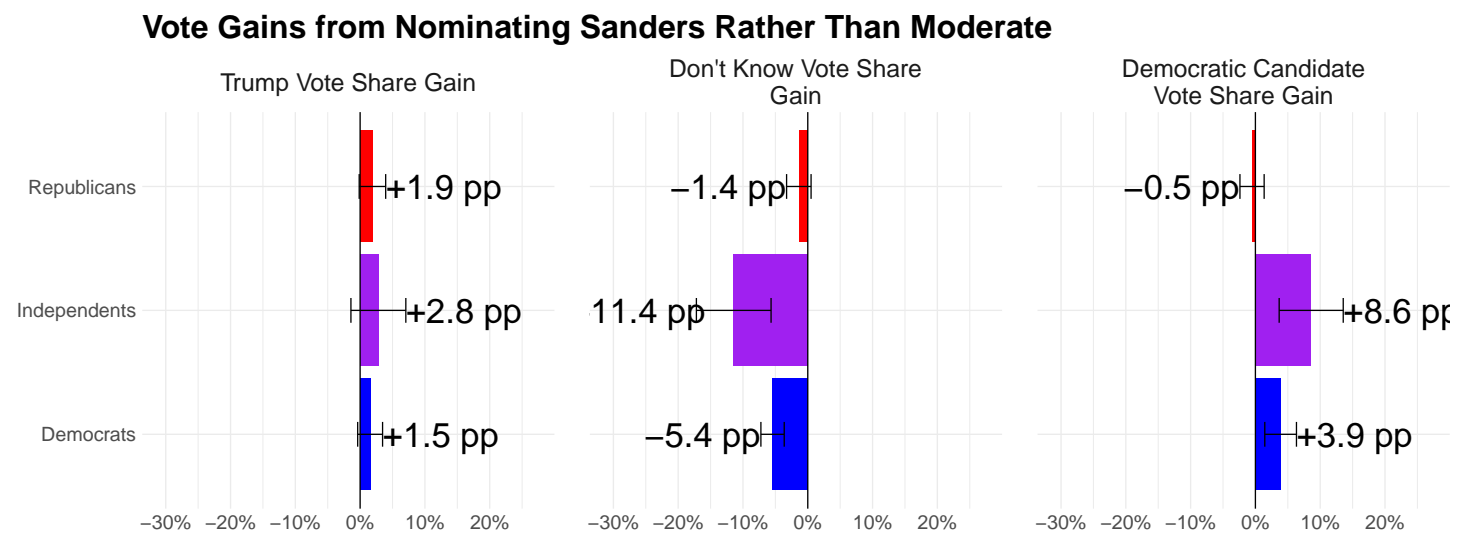

Notes: Each coefficient is from a separate regression conducted among the subgroup shown at left and where the dependent variable is 1 if the respondent selected the category shown at top and 0 otherwise. The regressions otherwise are identical to that shown in 2. 95\% confidence intervals surround point estimates. All regressions use General Population (ACS) weights. The regression results from which the coefficients reported in this Figure are drawn are reported in Table A7. 
likely to say they would vote for Trump if Sanders is the nominee instead of one of the moderates $(S E=0.0104, t=1.82)$, and 0.5 percentage points less likely to say they would vote Democratic if Sanders were the nominee $(S E=0.0095, t=-0.54)$.

These results are contrary to expectations of much of the behavioral literature but consistent with the literature on moderate candidates' advantages: in both datasets, an electorally significant share of Republicans say they will vote for one of the moderate Democrats, but return to saying they will vote for Donald Trump if Bernie Sanders is the Democratic nominee.

\section{Sanders' Ostensible Sources of Support}

Given the advantage among Republicans that moderate Democrats enjoy, why is Bernie Sanders' underperformance relative to the moderate Democrats not larger (see Figure 2)? We find that Sanders' relatively strong position appears to arise because many Democrats and Independents claimed they will not vote unless Sanders was the nominee. The bottom two rows of coefficients in Figures $3 \mathrm{a}$ and $3 \mathrm{~b}$ show this finding. In neither case do we find much evidence that Independents or Democrats would vote for Trump if a moderate Democrat were nominated. However, we do find that a large proportion of Democrats and Independents fall into the middle "don't know" or "undecided"/"would not vote" category if Sanders is not the nominee, whereas they say they would vote for Sanders if he is. In other words, Sanders appears to perform almost as well against Trump as moderates despite his losses among Republican voters because of a large share of Democrats and Independents who say they would only vote for him as the Democratic nominee. However, these voters do not say they would otherwise vote for Trump.

Is this offsetting dynamic plausible? Hall and Thompson (2018, Table 6) find that nominating an extremist candidate may have a positive though statistically insignificant effect on increasing own party turnout, although this effect is swamped by the much larger increase in opposing party turnout from nominating an extremist. In our data, we cannot rely on validated voter turnout because we are estimating counterfactual general election vote intentions. However, investigating 
which demographic groups convert from saying they are indifferent or would not vote to saying they would vote for Democrats when Sanders is in the head-to-head question can help inform the plausibility that Sanders is equally electable as the more moderate candidates.

In Figure 4, we show that Sanders' conversion of votes from the neither/would not vote category to the Democratic candidate category is driven in large part by Democrats and Independents under 35 years old ${ }^{15}$ In particular, Figure 4 replicates the same analysis as in Figure 3 but breaks down the results in each panel by different demographic categories instead of by respondent partisanship alone. The top two rows of each panel show that large increases in Sanders support and decreases in turnout intentions hold similarly for both white and non-white Democrats and Independents under 35. For both, the magnitude of this claimed increase in intent to turn out when Sanders is the nominee is extremely large, or around 11 percentage points on average.

The Nationscape data only provides a single "Don't know" option, but Figure A2 shows that, in our original survey data where more response options are available, these voters are most likely to say that they would not vote if Sanders is not nominated. In particular, these results are mostly driven by changes between the "Democratic candidate" and "Would not vote" category.

As some popular commentary speculated that Sanders had unique appeal among older white voters without a college degree, the third row of coefficients in Figure 4 shows that if anything the opposite is the case; in both the Nationscape and our original data, Trump receives more support when Sanders is the nominee. The same holds for the remainder of the samples.

In summary, concluding that Sanders appears almost as electable as the moderate candidates despite his losses among Republican voters appears to substantially rest on the supposition that young Democrats and Independents would turn out at approximately 11 percentage points higher rates if he were nominated.

\footnotetext{
${ }^{15}$ Age 35 is an arbitrary cut-off, of course, though many political campaigns define the "youth vote" as 18 to 35 . For example, see https://nextgenamerica.org/2020-yvip-primary/.
} 
Figure 4: Vote Choice by Demographics - Comparing Sanders and Moderate Candidates

(a) Nationscape

\section{Vote Gains from Nominating Sanders Rather Than A Moderate}

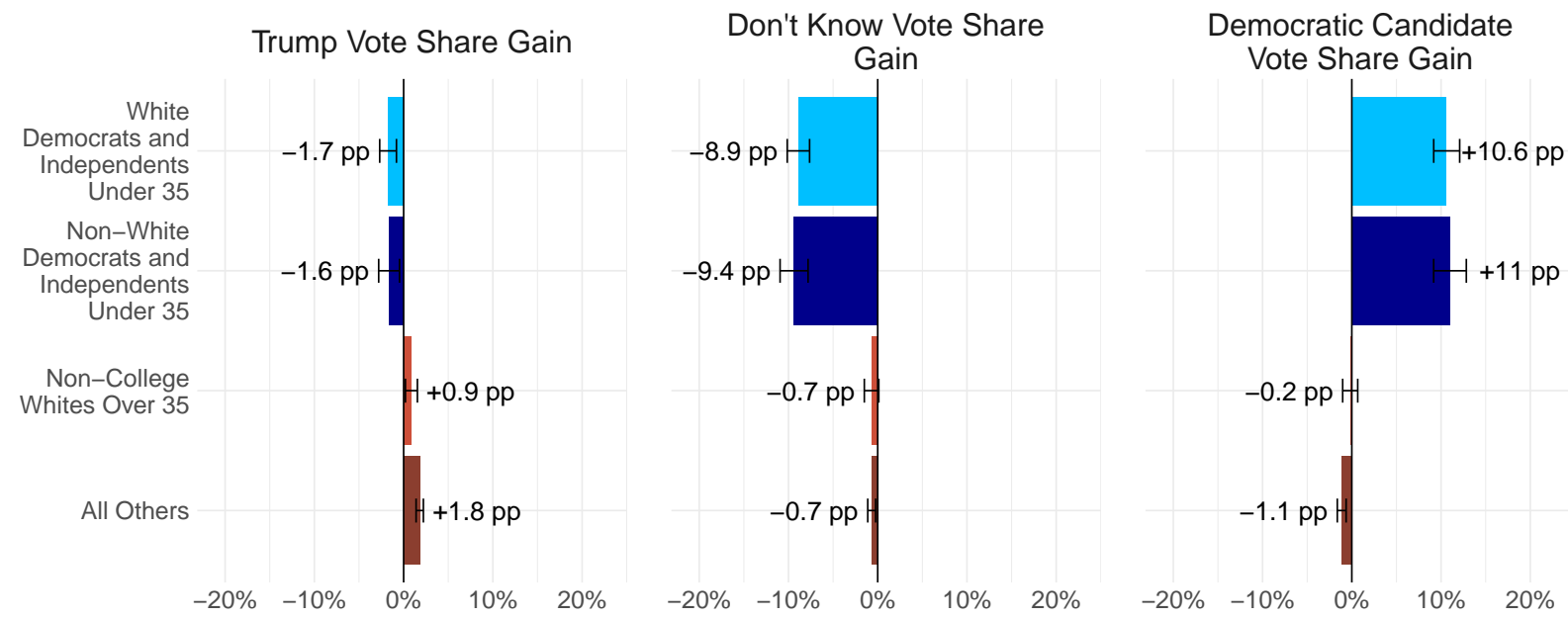

Notes: Each coefficient is from a separate regression conducted among the subgroup shown at left and where the dependent variable is 1 if the respondent selected the category shown at top and 0 otherwise. All regressions use the Nationscape included weights. The regressions otherwise are identical to that shown in 1.95\% confidence intervals surround point estimates. All regressions use Nationscape's included weights. The regression results from which the coefficients reported in this Figure are drawn are reported in Tables A8-11.

(b) Original Survey

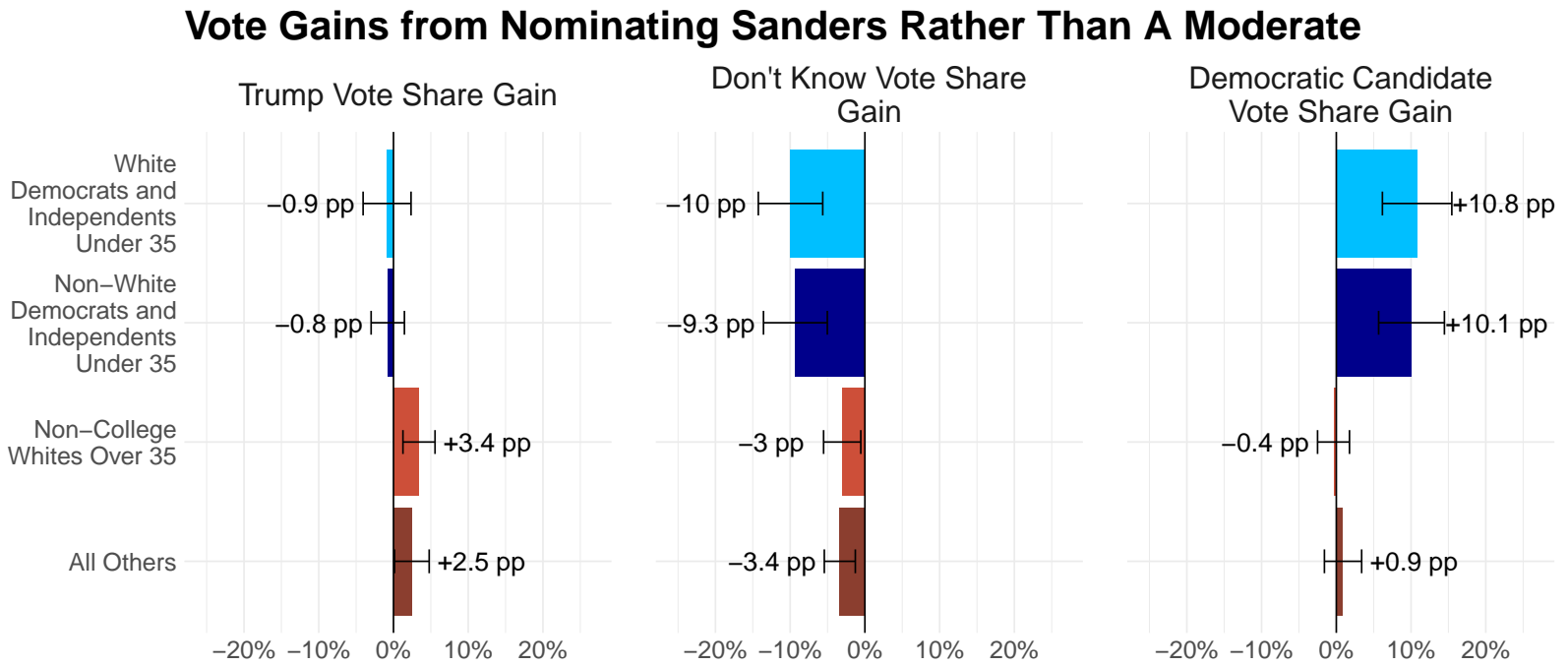

Notes: Each coefficient is from a separate regression conducted among the subgroup shown at left and where the dependent variable is 1 if the respondent selected the category shown at top and 0 otherwise. The regressions otherwise are identical to that shown in $2.95 \%$ confidence intervals surround point estimates. All regressions use General Population (ACS) weights. The regression results from which the coefficients reported in this Figure are drawn are reported in Tables A12-15. 
There are two reasons to doubt this would be the case. First, young Democrats and Independents have relatively low baseline turnout rates to begin with, so survey data that weights to the general population rather than prior electorates overstates the importance of their voting decisions. Second, self-reported intent to turn out correlates poorly with actual turnout decisions, suggesting we should not rely on survey-based estimates of turnout (Rogers and Aida 2014). Indeed, given that the surveys took place during the primary season when Sanders supporters might wish to strategically or expressively respond as if they would not turn out for other Democratic candidates, we may wish to be especially skeptical of self-reported turnout decisions.

To account for both of these points and examine the robustness of Sanders' apparently strong performance, we conduct an analysis where we adjust for turnout by weighting the sample to historical patterns of turnout and do not rely on respondent's self-reported turnout intentions. (We are only able to do this in our original data, not the Nationscape data. Given the Nationscape data's sampling design and the dataset's inclusion of existing weights, we cannot straightforwardly apply new weights to its existing weights that would adjust for turnout.)

Figure 5 shows the results. Each row in Figure 5 is the result of a separate regression estimated using Equation 2, The coefficients shown in the Figure estimate the effect of nominating Sanders instead of a moderate candidate on Democratic vote margin. The first coefficient is a baseline coefficient using the same weights as we use in the rest of the paper, weights constructed with general population as the target (as measured in the 2018 American Community Survey). The remaining rows apply various different approaches for weighting to likely turnout, discarding observations where respondents say they will not vote ${ }^{16}$ and weighting the remaining responses.

With these adjustments for likely turnout, Sanders consistently performs worse than the

\footnotetext{
${ }^{16}$ This coding decision was suggested by a reviewer. An alternative strategy would be to recode those who refuse to provide a preference as voting for their party. Doing so leads Sanders' vote share to fall even further below the moderate candidates', as this credits to the moderates the votes of the Democrats who say they would vote for Sanders but do not provide a preference when a moderate candidate is nominated.
} 
Figure 5: Estimated Effect of Nominating Sanders by Weighting Decision and Handling of "Neither"/"Will Not Vote" Responses

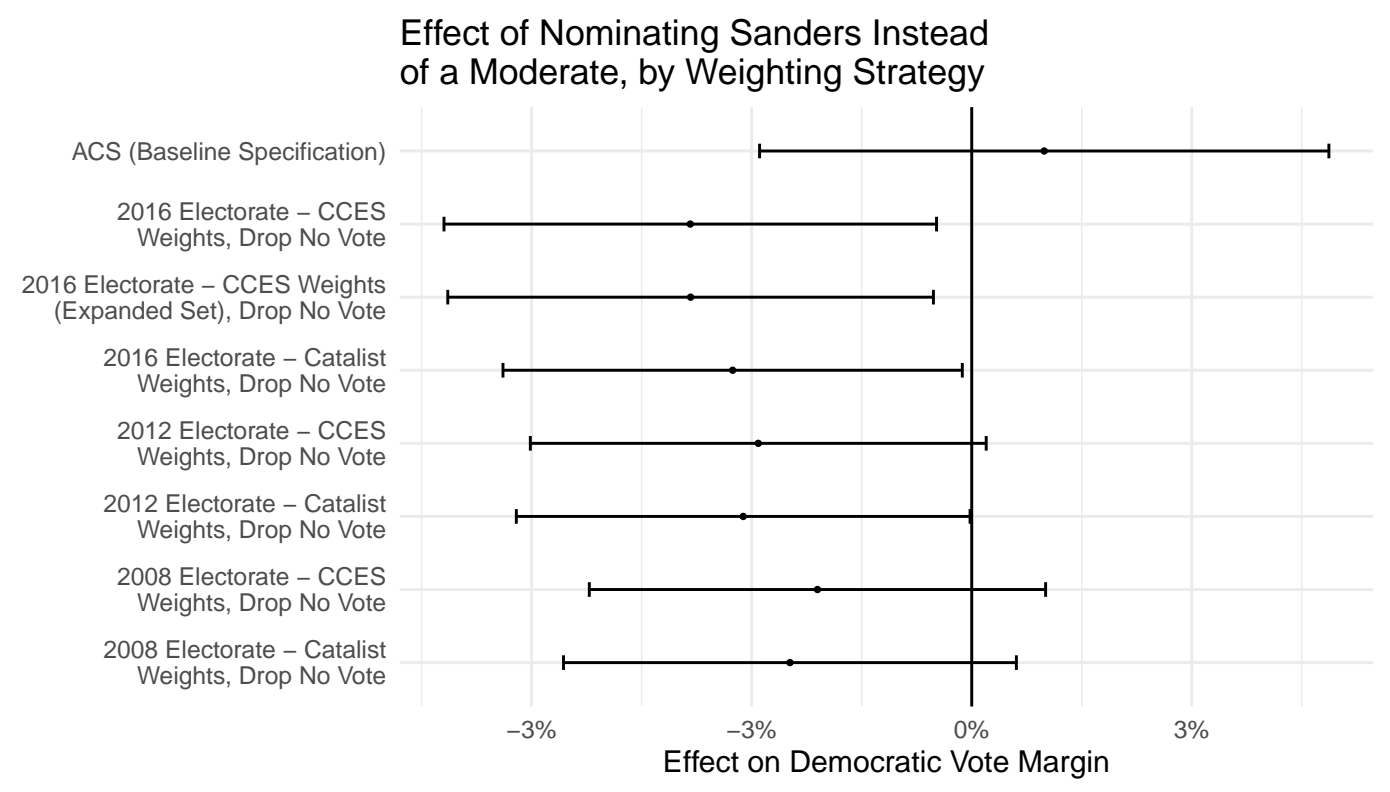

Notes: Each coefficient is from a separate regression conducted using the weights at left. The regressions otherwise are identical to that shown in 2, except the coefficient is on an indicator for 1 for respondents shown Sanders and 0 for respondents shown one of the three moderate candidates. 95\% confidence intervals surround point estimates. The regression results from which the coefficients reported in this Figure are drawn are reported in Table A16.

moderate candidates across all of the weights we consider. The "2016 Electorate - CCES" row uses the second set of weights we described earlier in the paper, which weight to the 2016 electorate as recorded by the CCES, and the following row uses the expanded set of weights from the 2016 CCES (the third set of weights we describe earlier in the paper). The following set of weights weights to the demographics of the 2016 electorate as indicated by Catalist. The remaining rows use the same strategy by weighting to the 2012 and 2008 electorates, again as indicated by the CCES each year and by Catalist.

In summary, concluding that Sanders would perform nearly as well as the more moderate candidates on the basis of our survey data appears to require assuming that nominating him would have increased turnout among Democrats and Independents under 35 by approximately 11 
percentage points, offsetting his inferior performance among the rest of the electorate.

There is good reason to doubt that nominating Sanders would have increased voter turnout among young Democrats and Independents by this large amount. This 11 percentage point increase would be significantly larger than the aggregate effects of entire Presidential campaigns on voter turnout (Enos and Fowler 2018), larger than the effects of nominating black candidates on black voter turnout (Washington 2006), larger than the increase in black turnout when Barack Obama ran for President in 2008, ${ }^{17}$ and approximately the size of the difference between typical midterm and Presidential general election turnout ${ }^{18}$ In addition, turnout in the 2020 Democratic primary itself suggests that a turnout boost of this magnitude would have been fairly unlikely to materialize solely due to Sanders' presence on the ballot: turnout in the 2020 Democratic primary did not exceeded 2008 levels, including among young voters ${ }^{19}$

\section{Discussion}

A prominent perspective in the American politics literature argues that more moderate candidates perform better in general elections, but this perspective faces skepticism from a behavioral literature that emphasizes voters' partisan loyalites. In addition, previous empirical research on candidate ideology and voter choice in American politics has largely focused on legislative elections given the paucity of data in other election types. Much of this research has also faced the challenge that extreme and moderate candidates may run in different elections at different times, confounding comparisons across types of candidates. There is also somewhat limited on

\footnotetext{
${ }^{17}$ Using validated voter turnout, McKee, Hood and Hill 2012. Table 2) find an 8 percentage point increase in African American turnout in Georgia from 2004 to 2008.

${ }^{18} \mathrm{See}$ http://www.electproject.org/home/voter-turnout/demographics for this and other comparisons.

${ }^{19}$ For example, turnout in the New Hampshire Democratic primary was 47\% in 2008, 40\% in 2016, and $43 \%$ in 2020. See https://twitter.com/jon_m_rob/status/1227600608888315904. 2020 numbers have been updated since the original tweet: youth turnout in New Hampshire was 19\% in 2020. The most recent comparable election is 2004, when youth turnout was $18 \%$. See https://circle.tufts.edu/latest-research/half-young-voters-back-sanders-propel-him -new-hampshire-victory. Also see https://www.nytimes.com/2020/02/24/us/politics/bernie-sanders-democratic-voter s.html and https://www.nytimes.com/2020/03/04/us/politics/bernie-sanders-young-voter-turnout.html
} 
data on whether changes in vote choice (i.e., persuasion) could contribute to any advantage moderate candidates have. To shed new light on the role of candidate ideology in American presidential elections, we exploit the unique circumstances of the 2020 Democratic primary: for a brief period, multiple candidates who were more moderate and more extreme could plausibly have won the same nomination to compete in the same general election; and, as we showed, voters largely recognized the ideological differences between them.

We presented data from both an original survey and an existing survey on how a large sample of voters said they would choose in a general election between one of these candidates and incumbent Donald Trump. Our findings were broadly consistent with expectations from the American politics literature that more moderate candidates should win more support in general elections than more extreme candidates. Incumbent Donald Trump received significantly more support from survey respondents asked to choose between Trump and an extreme Democrat than Trump and a moderate Democrat.

Our findings provide three main pieces of insight into the broader literature on candidate ideology in elections. First, our findings are consistent with a prominent perspective in the American politics literature that has argued moderate candidates perform better in general elections, and provide new evidence that this holds in the context of Presidential elections. Second, our findings that outpartisans (in this case, Republicans) drove this advantage by crossing party lines to say they would support an outpartisan moderate candidate (in this case, a Democrat) but not an extreme one are inconsistent with claims in the behavioral literature that "partisan intoxication" completely overrides voters' concerns with candidates' policy positions (for review and critique, see Fowler et al. 2020). Third, this same finding suggests that, at least in Presidential elections, moderate candidates' advantages may arise in part from a persuasion or vote-switching mechanism. The existing literature on candidate ideology in elections has generally relied on actual election returns which, while having many advantages, makes it difficult to determine whether changes in turnout or persuasion are responsible for moderate candidates' electoral 
advantages (for general discussion, see Hill, Hopkins and Huber 2021). While Hall and Thompson (2018) find that turnout patterns best explain this electoral penalty in congressional races, their standard errors are large enough that small but significant persuasion effects would be hard to detect. In the case of the 2020 presidential election, we find evidence for a persuasion or vote-switching mechanism: a small, but electorally consequential percentage of Republican voters indicated they would vote for Trump against a more extreme Democratic candidate but that they would otherwise vote for a more moderate Democrat. In summary, evidence therefore suggests that both a turnout (per Hall and Thompson 2018) and a persuasion mechanism might operate in granting moderates an electoral advantage.

With this said, we again hasten to re-emphasize the caveats and limitations we noted at the outset, especially that our evidence comes from only one set of candidates in one election, is survey-based in nature and so could be affected by expressive or strategic responding, and is not well-suited to capturing equilibrium effects.

Our data also cannot speak to why ideologically moderate candidates may be more successful at persuading outpartisans to vote for them than ideologically extreme candidates-i.e., the mechanisms underpinning many voters' preferences for them. We encourage future work to explore how and to what extent policy positions, fundraising, media coverage, candidate quality, and other factors might explain the electoral penalty we find here.

We close by considering the substantive significance of our estimates. The effect size we observed was small in absolute terms and would be difficult to detect in typically sized surveys. But an effect this small would be enormously consequential in competitive elections. Indeed, in the 2020 US Presidential election, the states of Georgia, Wisconsin, and Arizona were all ultimately decided by less than 0.63 percentage points on vote margin. If these three states had voted for Donald Trump, which would have required only 1 in 300 voters in these states to change their vote, he would have been re-elected in 2020. It is of course impossible to know whether our estimate that approximately $2 \%$ of Republicans would have voted for Trump were Sanders the Democratic 
nominee would generalize to actual voting behavior in the 2020 US Presidential election. However, if even one half of these $2 \%$ of Republicans actually would have engaged in this behavior, all else equal Sanders' nomination could have resulted in Trump's victory. ${ }^{20}$

\section{References}

Abramowitz, Alan I. 2019. "Medicare for All a Vote Loser in 2018 U.S. House

Elections.” Available at http://centerforpolitics.org/crystalball/articles/medicare-for-all-a-vote-1 oser-in-2018-u-s-house-elections/.

Achen, Christopher H. and Larry M. Bartels. 2016. Democracy for Realists: Why Elections Do

Not Produce Responsive Government. Princeton, NJ: Princeton University Press.

Ansolabehere, Stephen and Brian F. Schaffner. 2017. “CCES Common Content, 2016.”.

URL: https://doi.org/10.7910/DVN/GDF6Z0

Ansolabehere, Stephen, James M. Snyder and Charles Stewart. 2001. "Candidate Positioning in US House Elections." American Journal of Political Science 45(1):136-159.

Broockman, David and Joshua Kalla. 2020. “When and Why Are Campaigns' Persuasive Effects Small? Evidence from the 2020 US Presidential Election.”.

Bullock, John G., Alan S. Gerber, Seth J. Hill and Gregory A. Huber. 2015. "Partisan Bias in Factual Beliefs about Politics.” Quarterly Journal of Political Science 10:519-578.

\footnotetext{
${ }^{20}$ Based on data of the partisan composition of the 2020 electorate from TargetSmart, Biden's margin in Arizona was 10,457 and TargetSmart estimates at least 1,387,889 modeled Republicans voted in 2020. Biden's margin in Georgia was 11,779 and TargetSmart estimates at least 1,984,207 modeled Republicans voted in 2020. Biden's margin in Wisconsin was 20,682 and TargetSmart estimates at least 722,145 modeled Republicans voted in 2020. Data from https://targetearly.targetsmart.com/historic.html. Note that for each voter who switches from voting for the Democrat to the Republican, this decreases Democratic vote margin by two, as it both subtracts one from the Democratic total and adds one to the Republican total.
} 
Campbell, Angus, Philip E. Converse, Warren E. Miller and Donald E. Stokes. 1960. The American Voter. Chicago.

Canes-Wrone, Brandice, David W. Brady and John F. Cogan. 2002. “Out of Step, Out of Office: Electoral Accountability and House Members' Voting." American Political Science Review 96(1):127-140.

Cohen, Marty, Mary C. McGrath, Peter Aronow and John Zaller. 2016. "Ideologically extreme candidates in US presidential elections, 1948-2012." The ANNALS of the American Academy of Political and Social Science 667(1):126-142.

Coppock, Alexander and Oliver A. McClellan. 2019. "Validating the demographic, political, psychological, and experimental results obtained from a new source of online survey respondents.” Research \& Politics 6(1):2053168018822174.

Enos, Ryan D. and Anthony Fowler. 2018. "Aggregate effects of large-scale campaigns on voter turnout." Political Science Research and Methods 6(4):733-751.

Fowler, Anthony. 2013. "Electoral and policy consequences of voter turnout: Evidence from compulsory voting in Australia.” Quarterly Journal of Political Science 8(2):159-182.

Fowler, Anthony et al. 2020. "Partisan intoxication or policy voting?" Quarterly Journal of Political Science 15(2):141-179.

Hainmueller, Jens. 2012. "Entropy Balancing for Causal Effects: A Multivariate Reweighting Method to Produce Balanced Samples in Observational Studies." Political Analysis 20(1):2546.

Hall, Andrew B. 2015. "What Happens When Extremists Win Primaries?" American Political Science Review 109(1):18-42. 
Hall, Andrew B. and Daniel M. Thompson. 2018. "Who punishes extremist nominees? Candidate ideology and turning out the base in US elections." American Political Science Review 112(3):509-524.

Hill, Seth J. 2017. "Changing votes or changing voters? How candidates and election context swing voters and mobilize the base." Electoral Studies 48:131-148.

Hill, Seth J, Daniel J Hopkins and Gregory A Huber. 2021. "Not by turnout alone: Measuring the sources of electoral change, 2012 to 2016." Science Advances 7(17):eabe3272.

Kalla, Joshua and David Broockman. 2020. "Which narrative strategies durably reduce prejudice? Evidence from field and survey experiments supporting the efficacy of perspective-getting.".

Lenz, Gabriel S. 2012. Follow the Leader? How Voters Respond to Politicians' Performance and Policies. Chicago: University of Chicago Press.

Lo, James et al. 2013. "Legislative responsiveness to gerrymandering: Evidence from the 2003 Texas redistricting." Quarterly Journal of Political Science 8(1):75-92.

McDonald, Jared. 2020. "Avoiding the Hypothetical: Why "Mirror Experiments" are an Essential Part of Survey Research.” International Journal of Public Opinion Research 32(2):266-283.

McKee, Seth C., M.V. Hood and David Hill. 2012. "Achieving validation: Barack Obama and black turnout in 2008." State Politics \& Policy Quarterly 12(1):3-22.

Rogers, Todd and Masahiko Aida. 2014. "Vote self-prediction hardly predicts who will vote, and is (misleadingly) unbiased.” American Politics Research 42(3):503-528.

Tausanovtich, Chris, Lynn Vavreck, Tyler Reny, Alex Hayes and Aaron Rudkin. 2019. "Democracy Fund+ UCLA Nationscape: Methodology and Representativeness Assessment.”. 
Washington, Ebonya. 2006. "How black candidates affect voter turnout." The Quarterly Journal of Economics 121(3):973-998. 


\section{Online Appendix}

\section{Contents}

\begin{tabular}{|lr|}
\hline A Additional Tables and Figures & 2
\end{tabular}

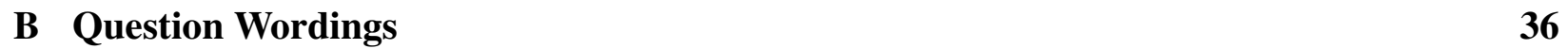




\section{A Additional Tables and Figures}

Table A1: National polling averages in Democratic primary according to FiveThirtyEight, as of January 21, 2020

\begin{tabular}{ccc}
\hline Candidate & National Polling Average & Included in Paper? \\
\hline Biden & $26.7 \%$ & $\checkmark$ \\
Sanders & $19.3 \%$ & $\checkmark$ \\
Warren & $16.0 \%$ & $\checkmark$ \\
Buttigieg & $7.3 \%$ & $\checkmark$ \\
Bloomberg & $7.0 \%$ & $\checkmark$ \\
Yang & $3.8 \%$ & - \\
Klobuchar & $2.9 \%$ & - \\
Steyer & $2.4 \%$ & - \\
Gabbard & $1.8 \%$ & - \\
Bennet & $0.5 \%$ & - \\
Delaney & $0.5 \%$ & - \\
Patrick & $0.3 \%$ & - \\
\hline
\end{tabular}

Notes: Checkmarks appear next to the candidates we analyze matchups with Trump with in the Nationscape data and that we asked about in our original survey.

Source: https://projects.fivethirtyeight.com/polls/president-primary-d/national/.

Table A2: Share of respondents who say that the row candidate is as liberal or more liberal than the column candidate.

\begin{tabular}{l|llllll} 
& Sanders & Warren & Buttigieg & Biden & Bloomberg & Trump \\
\hline \multirow{2}{*}{ Sanders } & - & $86.3 \%$ & $88.1 \%$ & $88.2 \%$ & $89.1 \%$ & $89.3 \%$ \\
& & $(1684)$ & $(1521)$ & $(1807)$ & $(1672)$ & $(1822)$ \\
\multirow{3}{*}{ Warren } & $61.6 \%$ & & $84.0 \%$ & $85.5 \%$ & $86.8 \%$ & $89.7 \%$ \\
& $(1684)$ & & $(1464)$ & $(1661)$ & $(1566)$ & $(1627)$ \\
Buttigieg & $41.5 \%$ & $54.1 \%$ & & $77.7 \%$ & $81.2 \%$ & $89.4 \%$ \\
& $(1521)$ & $(1464)$ & - & $(1492)$ & $(1439)$ & $(1465)$ \\
Biden & $37.9 \%$ & $48.9 \%$ & $63.3 \%$ & & $77.3 \%$ & $88.6 \%$ \\
& $(1807)$ & $(1661)$ & $(1492)$ & - & $(1642)$ & $(1747)$ \\
Bloomberg & $36.6 \%$ & $44.8 \%$ & $56.1 \%$ & $63.6 \%$ & & $87.2 \%$ \\
\multirow{3}{*}{ Trump } & $(1672)$ & $(1566)$ & $(1439)$ & $(1642)$ & - & $(1629)$ \\
& $15.3 \%$ & $14.8 \%$ & $16.2 \%$ & $18.7 \%$ & $21.6 \%$ & - \\
\hline
\end{tabular}

Notes: This reports the same data as in Figure 1, but by pairwise comparison. Sample sizes for each comparison are in parentheses. This is calculated without weighting and excluding respondents who did not know each candidate ideology. 
Table A3: Descriptive Statistics by Survey Weights

\begin{tabular}{lccc}
\hline \hline & $\begin{array}{c}\text { Unweighted } \\
\text { Mean }\end{array}$ & $\begin{array}{c}\text { National Weight (ACS) } \\
\text { Mean }\end{array}$ & $\begin{array}{c}\text { 2016 Electorate Weight (CCES) } \\
\text { Mean }\end{array}$ \\
\hline Male & 0.37 & 0.49 & 0.47 \\
Age 18-24 & 0.19 & 0.12 & 0.08 \\
Age 25-34 & 0.21 & 0.18 & 0.14 \\
Age 35-44 & 0.18 & 0.16 & 0.14 \\
Age 45-64 & 0.27 & 0.33 & 0.41 \\
Age 65 and older & 0.14 & 0.21 & 0.24 \\
White some high school or less & 0.02 & 0.04 & 0.06 \\
White high school graduate & 0.18 & 0.17 & 0.23 \\
White completed some college & 0.16 & 0.13 & 0.18 \\
White Associate's degree & 0.07 & 0.06 & 0.08 \\
White Bachelor's degree & 0.18 & 0.14 & 0.15 \\
White Graduate degree & 0.10 & 0.09 & 0.09 \\
African-American & 0.09 & 0.12 & 0.11 \\
Hispanic & 0.09 & 0.15 & 0.05 \\
Asian & 0.04 & 0.06 & 0.02 \\
Native American & 0.01 & 0.01 & 0.01 \\
Mixed or other race & 0.05 & 0.04 & 0.03 \\
Democrat (including leaners) & 0.45 & 0.45 & 0.41 \\
Pure Independent & 0.16 & 0.15 & 0.15 \\
Republican (including leaners) & 0.39 & 0.39 & 0.43 \\
\hline Observations & 40150 & 40150 & 40150 \\
\hline \hline
\end{tabular}


Figure A1: Perceptions of Candidate Ideology, by Party

\section{Candidate Perception}

Among Democrats

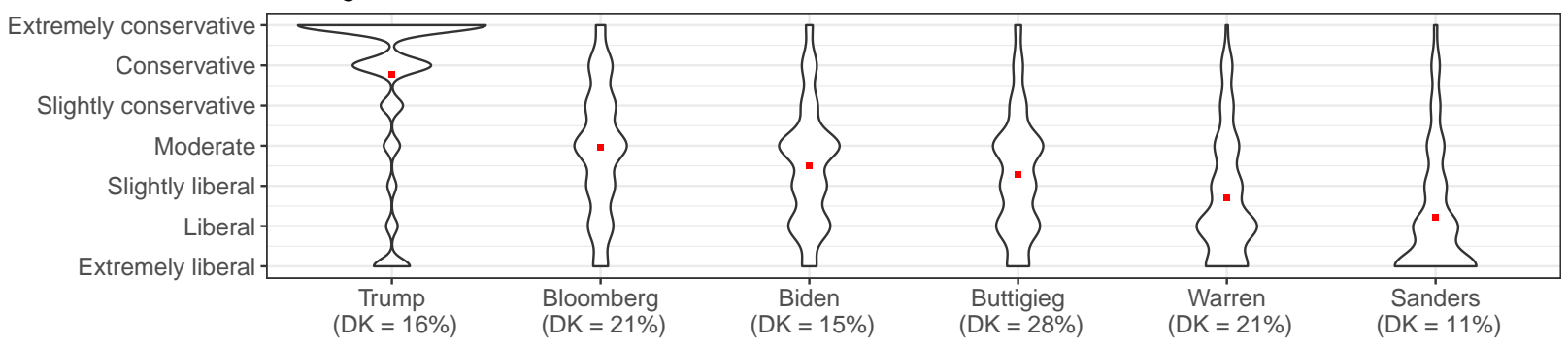

Among Republicans

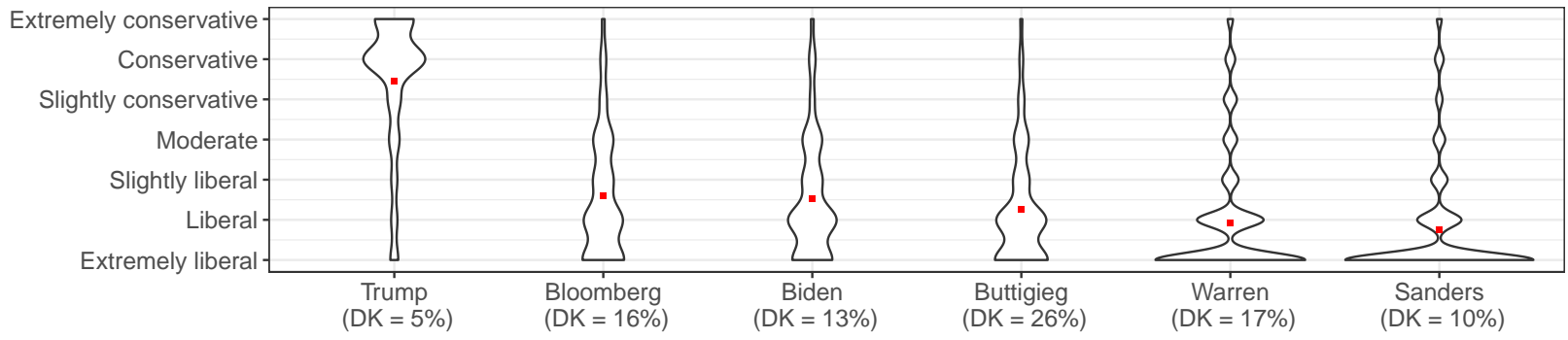

Among Independents

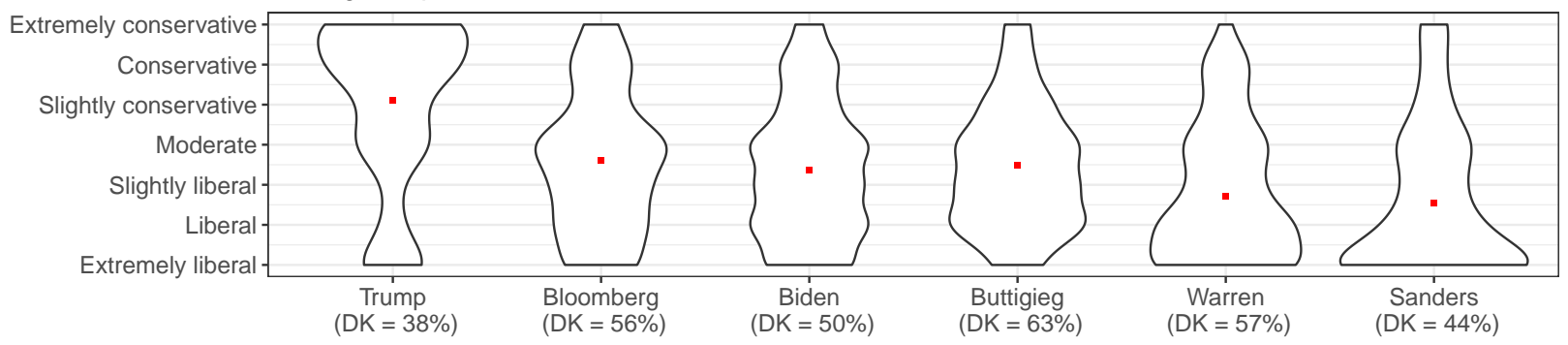

Note: Each plot shows the distribution of responses by candidate.

The red square is the mean. This is calculated excluding respondents who did not know.

Notes: This reports Figure 1 in the main text, but broken down by respondent party. 
Figure A2: Among Under 35 Democrats and Independents - Comparing Sanders and Moderate Candidates

\section{Effect of Bernie Sanders vs. More Moderate Democratic Candidate on Head-to-Head vs. Trump Under 35 Democrats and Independents Only}

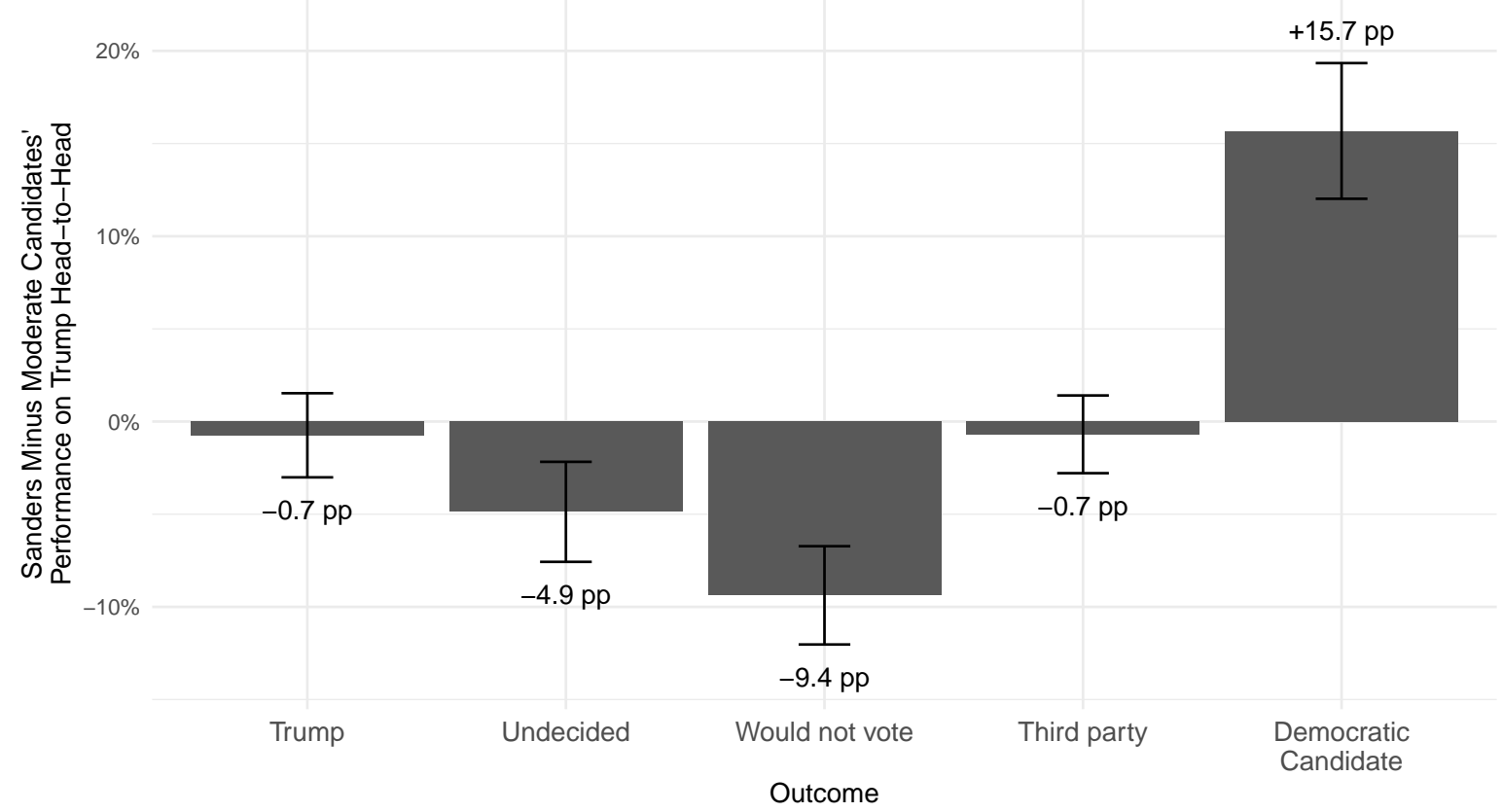

Notes: 95\% confidence intervals surround point estimates. This Figure uses General Population (ACS) weights. Figure 4 uses the entire dataset whereas this Figure uses only the second half of the data, which included an explicit "I would not vote" option; this is why Sanders' effect on Democratic votes among this subgroup is not identical to the number in Figure 4. 
Table A4: Numerical Estimates for Figure 2A

(1)

Dem vs. Trump Vote Margin (-1/0/1) Dem vs. Trump Vote Margin (-1/0/1)

Not Moderate

(.)

Yes Moderate

$0.0088^{* *}$

$(0.0028)$

Biden

Bloomberg

Buttigieg

Sanders

Warren

Constant

$0.0650^{* * *}$

$(0.0015)$

Observations

$R^{2}$

217622

0.884
(.)

$-0.0086$

(0.0057)

$-0.0487^{* * *}$

$(0.0043)$

$-0.0089^{*}$

(0.0035)

$-0.0517^{* * *}$

(0.0042)

$0.0904^{* * *}$

(0.0022)

217622

0.884

Standard errors in parentheses

${ }^{*} p<0.05,{ }^{* *} p<0.01,{ }^{* * *} p<0.001$ 
Table A5: Numerical Estimates for Figure 2B

(1)

(2)

Dem vs. Trump Vote Margin (-1/0/1) Dem vs. Trump Vote Margin (-1/0/1)

Not Moderate

(.)

Yes Moderate

0.0100

$(0.0096)$

Joe Biden

(.)

Michael Bloomberg

$0.0392^{* *}$

$(0.0145)$

Pete Buttigieg

0.0025

$(0.0145)$

Elizabeth Warren

$-0.0125$

$(0.0137)$

Bernie Sanders

0.0208

$(0.0155)$

Northeast

(.)

(.)

Midwest

$-0.0031$

$-0.0027$

(0.0137)

(0.0137)

South

$-0.0047$

$-0.0040$

(0.0132)

(0.0132)

West

$-0.0087$

$-0.0084$

(0.0155)

(0.0155) 


\begin{tabular}{|c|c|c|}
\hline \multirow[t]{2}{*}{ White } & - & - \\
\hline & (.) & (.) \\
\hline \multirow[t]{2}{*}{ Black } & $0.0393^{*}$ & $0.0385^{*}$ \\
\hline & $(0.0161)$ & $(0.0161)$ \\
\hline \multirow[t]{2}{*}{ American Indian } & -0.0071 & -0.0089 \\
\hline & $(0.0471)$ & $(0.0470)$ \\
\hline \multirow[t]{2}{*}{ Asian } & 0.0134 & 0.0127 \\
\hline & $(0.0265)$ & $(0.0264)$ \\
\hline \multirow[t]{2}{*}{ Other } & 0.0104 & 0.0109 \\
\hline & $(0.0229)$ & $(0.0228)$ \\
\hline \multirow[t]{2}{*}{ Hispanic } & 0.0029 & 0.0023 \\
\hline & $(0.0196)$ & $(0.0197)$ \\
\hline \multirow[t]{2}{*}{ Some high school } & - & - \\
\hline & (.) & (.) \\
\hline \multirow[t]{2}{*}{ High school } & 0.0012 & 0.0010 \\
\hline & $(0.0253)$ & $(0.0253)$ \\
\hline \multirow[t]{2}{*}{ Other post high school } & 0.0133 & 0.0146 \\
\hline & $(0.0303)$ & $(0.0302)$ \\
\hline \multirow[t]{2}{*}{ Some college } & -0.0122 & -0.0124 \\
\hline & $(0.0257)$ & $(0.0257)$ \\
\hline \multirow[t]{2}{*}{ Associates Degree } & -0.0188 & -0.0189 \\
\hline & $(0.0282)$ & $(0.0282)$ \\
\hline \multirow[t]{2}{*}{ Bachelors Degree } & 0.0088 & 0.0087 \\
\hline & $(0.0264)$ & $(0.0264)$ \\
\hline Masters or Professional & -0.0133 & -0.0132 \\
\hline
\end{tabular}




\begin{tabular}{|c|c|c|}
\hline & $(0.0302)$ & $(0.0302)$ \\
\hline \multirow[t]{2}{*}{ Doctorate } & 0.0414 & 0.0408 \\
\hline & $(0.0435)$ & $(0.0435)$ \\
\hline \multirow[t]{2}{*}{ Age } & $-0.0007^{*}$ & $-0.0007^{*}$ \\
\hline & $(0.0003)$ & $(0.0003)$ \\
\hline \multirow[t]{2}{*}{ Gender } & -0.0163 & -0.0157 \\
\hline & $(0.0093)$ & $(0.0093)$ \\
\hline \multirow[t]{2}{*}{ Household Income } & 0.0004 & 0.0003 \\
\hline & $(0.0009)$ & (0.0009) \\
\hline \multirow[t]{2}{*}{ Ideology } & -0.0023 & -0.0023 \\
\hline & $(0.0061)$ & $(0.0061)$ \\
\hline \multirow[t]{2}{*}{ US House Dem } & - & - \\
\hline & (.) & (.) \\
\hline \multirow[t]{2}{*}{ US House Not Sure } & $-0.2832^{* * *}$ & $-0.2850^{* * *}$ \\
\hline & $(0.0242)$ & $(0.0243)$ \\
\hline \multirow[t]{2}{*}{ US House GOP } & $-0.5151^{* * *}$ & $-0.5184^{* * *}$ \\
\hline & $(0.0347)$ & $(0.0346)$ \\
\hline \multirow[t]{2}{*}{ Clinton } & - & - \\
\hline & (.) & (.) \\
\hline \multirow[t]{2}{*}{ Other } & $-0.1301^{* * *}$ & $-0.1289^{* * *}$ \\
\hline & $(0.0177)$ & $(0.0177)$ \\
\hline \multirow[t]{2}{*}{ Trump } & $-0.3906^{* * *}$ & $-0.3896^{* * *}$ \\
\hline & $(0.0304)$ & $(0.0303)$ \\
\hline \multirow[t]{2}{*}{ Econ Perception Today } & -0.0117 & -0.0117 \\
\hline & $(0.0076)$ & $(0.0076)$ \\
\hline
\end{tabular}




\begin{tabular}{|c|c|c|}
\hline \multirow[t]{2}{*}{ Econ Perception Future } & 0.0038 & 0.0033 \\
\hline & $(0.0079)$ & $(0.0079)$ \\
\hline \multirow[t]{2}{*}{ Personanl Finance } & 0.0051 & 0.0050 \\
\hline & $(0.0066)$ & $(0.0066)$ \\
\hline \multirow[t]{2}{*}{ Right-Wing Auth } & $0.0347^{* * *}$ & $0.0345^{* * *}$ \\
\hline & $(0.0092)$ & $(0.0092)$ \\
\hline \multirow[t]{2}{*}{ Trump Favorability } & $-0.1664^{* * *}$ & $-0.1661^{* * *}$ \\
\hline & $(0.0060)$ & $(0.0060)$ \\
\hline \multirow[t]{2}{*}{ Police Favorability } & 0.0065 & 0.0064 \\
\hline & $(0.0035)$ & $(0.0035)$ \\
\hline \multirow[t]{2}{*}{ Congress Favorability } & $0.0282^{* * *}$ & $0.0281^{* * *}$ \\
\hline & $(0.0034)$ & $(0.0034)$ \\
\hline \multirow[t]{2}{*}{ Strong Dem } & - & - \\
\hline & $()$. & $()$. \\
\hline \multirow[t]{2}{*}{ Not strong Dem } & -0.0190 & -0.0185 \\
\hline & $(0.0184)$ & $(0.0185)$ \\
\hline \multirow[t]{2}{*}{ Lean Dem } & 0.0102 & 0.0110 \\
\hline & $(0.0178)$ & $(0.0179)$ \\
\hline \multirow[t]{2}{*}{ Neither } & $-0.1304^{* * *}$ & $-0.1292^{* * *}$ \\
\hline & $(0.0248)$ & $(0.0248)$ \\
\hline \multirow[t]{2}{*}{ Lean GOP } & $-0.2171^{* * *}$ & $-0.2161^{* * *}$ \\
\hline & $(0.0332)$ & $(0.0332)$ \\
\hline \multirow[t]{2}{*}{ Not strong GOP } & $-0.1919^{* * *}$ & $-0.1920^{* * *}$ \\
\hline & $(0.0296)$ & $(0.0295)$ \\
\hline Strong GOP & $-0.1418^{* * *}$ & $-0.1415^{* * *}$ \\
\hline
\end{tabular}




\begin{tabular}{lcc}
\hline & $(0.0323)$ & $(0.0323)$ \\
Constant & $1.1117^{* * *}$ & $1.1076^{* * *}$ \\
& $(0.0415)$ & $(0.0424)$ \\
\hline Observations & 12725 & 12725 \\
$R^{2}$ & 0.791 & 0.791 \\
\hline \hline
\end{tabular}

Standard errors in parentheses

${ }^{*} p<0.05,{ }^{* *} p<0.01,{ }^{* * *} p<0.001$ 


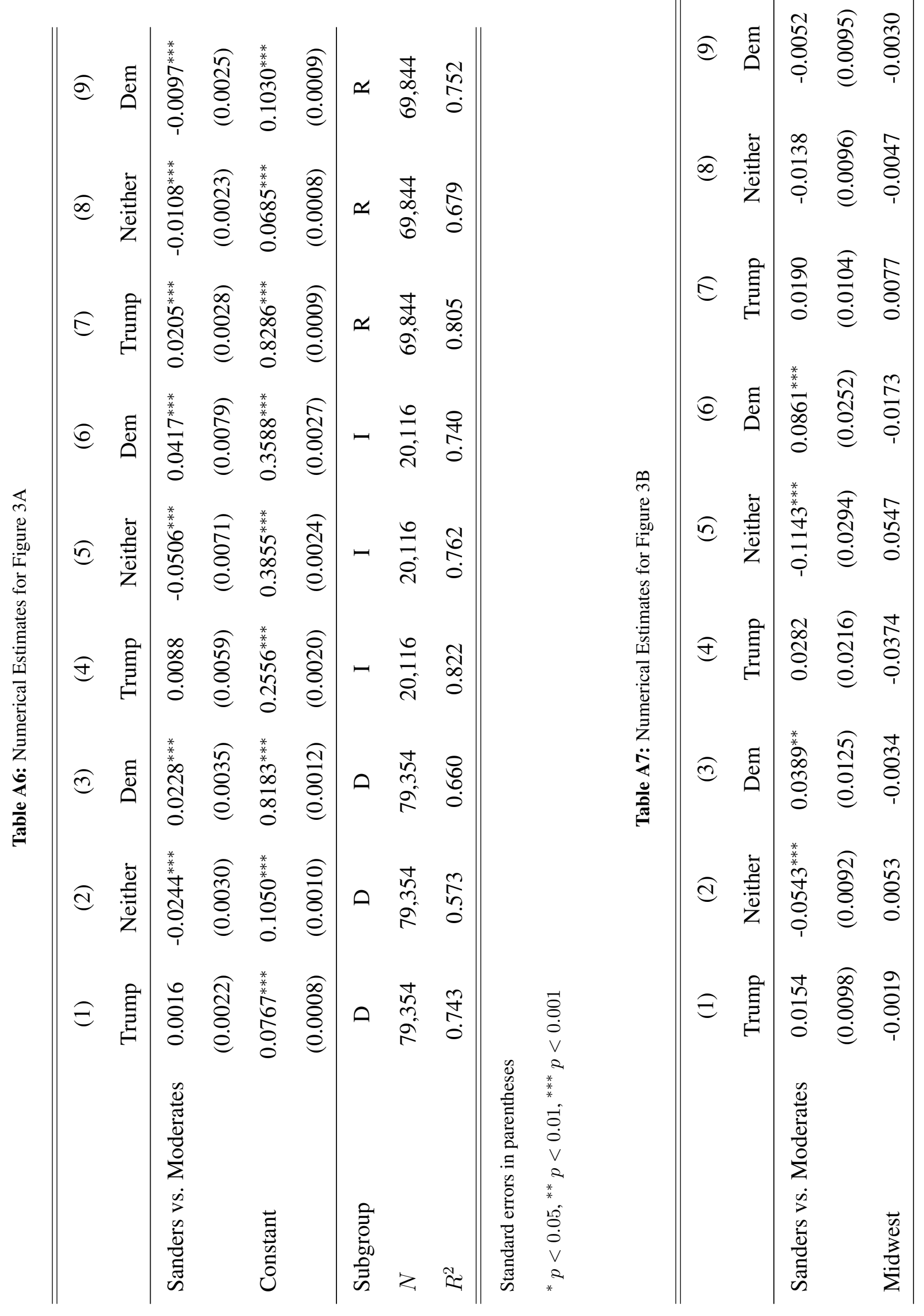




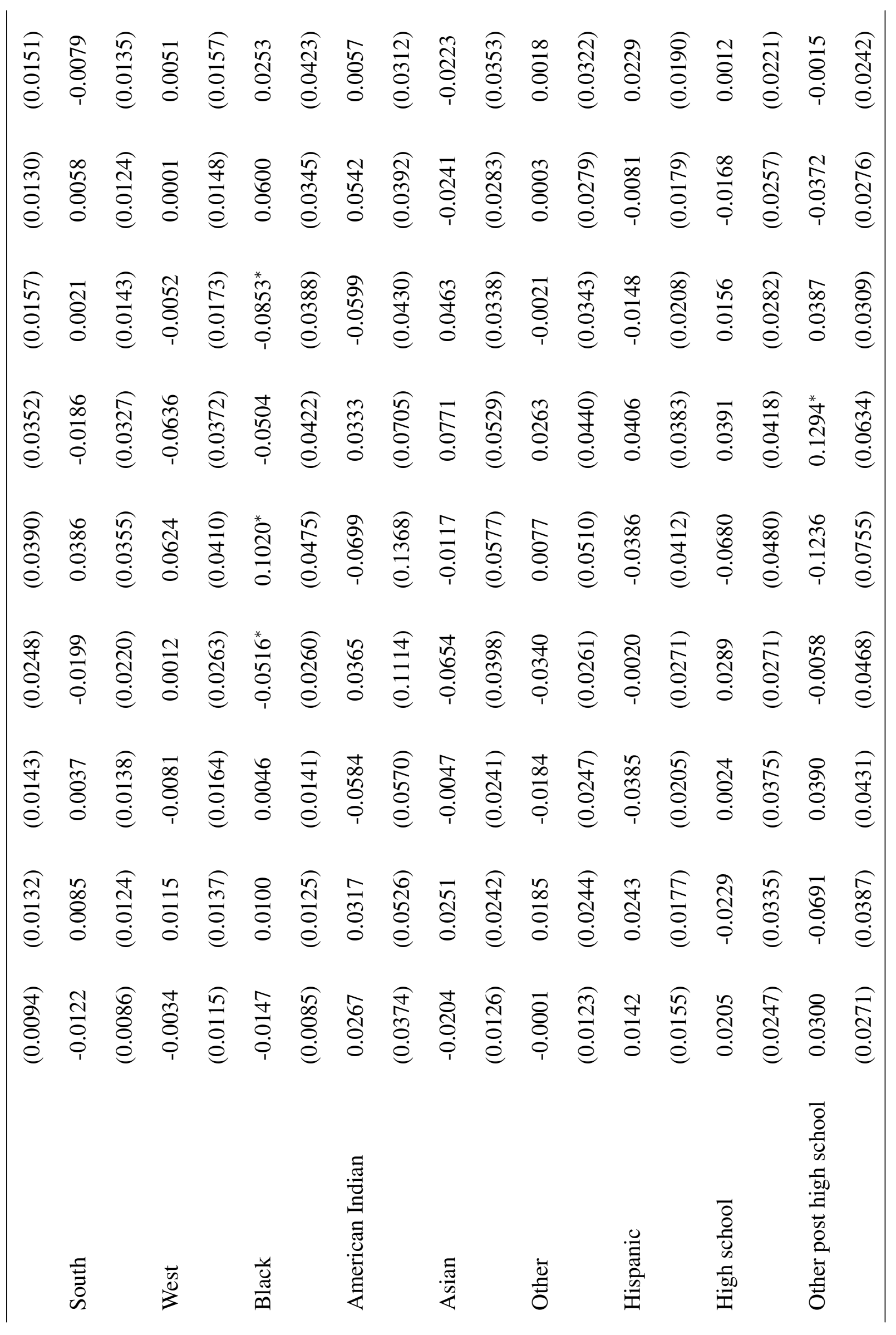




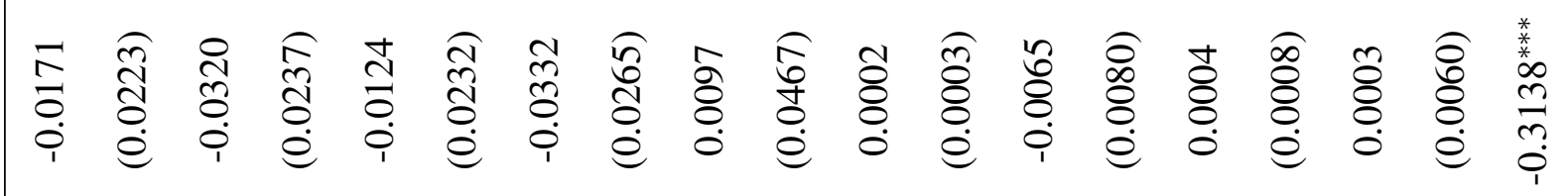

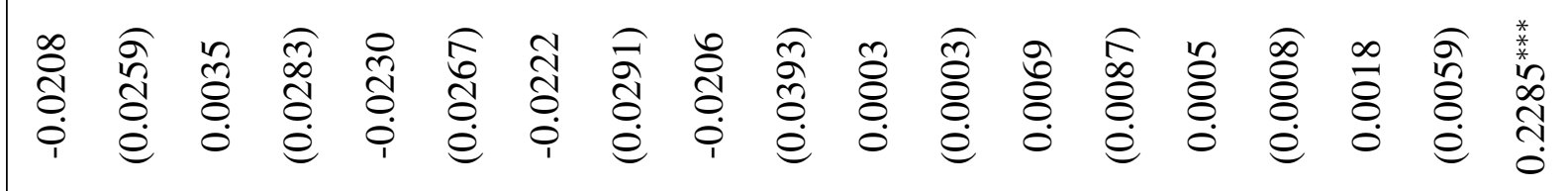

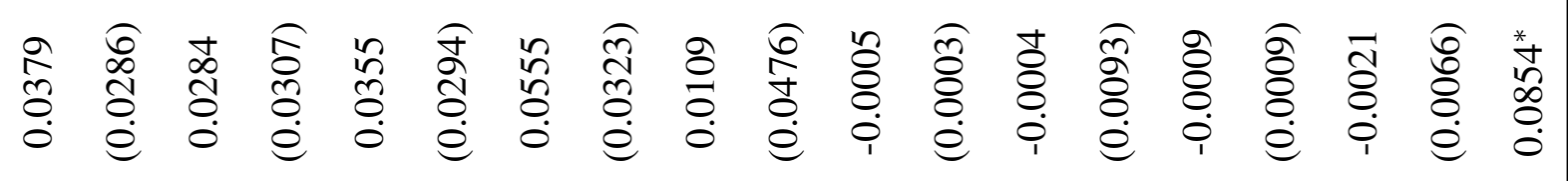

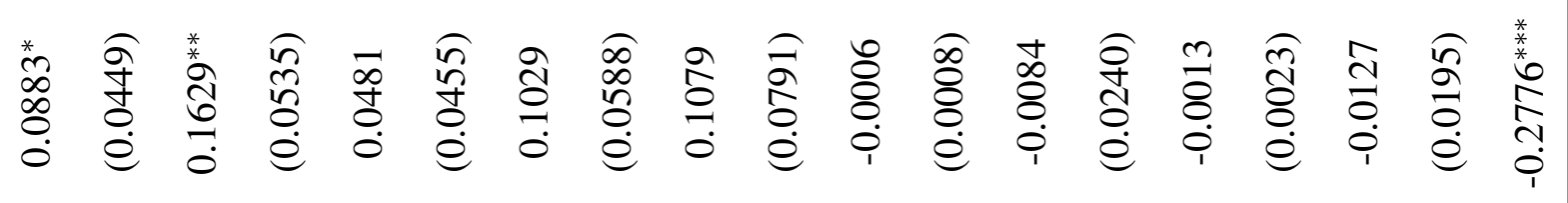

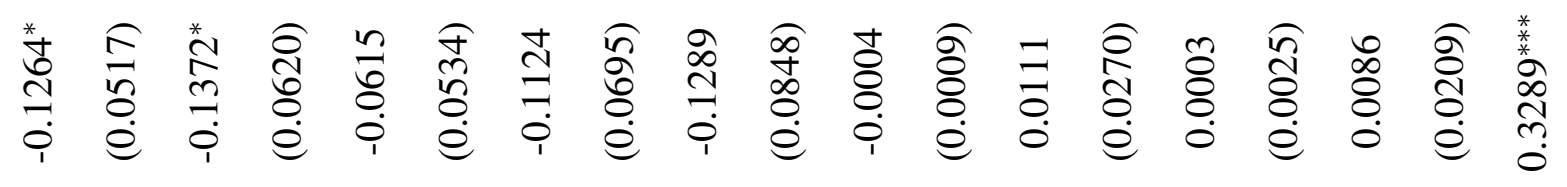

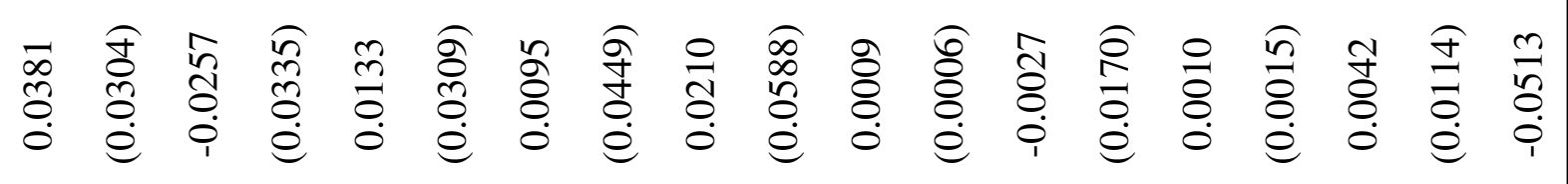

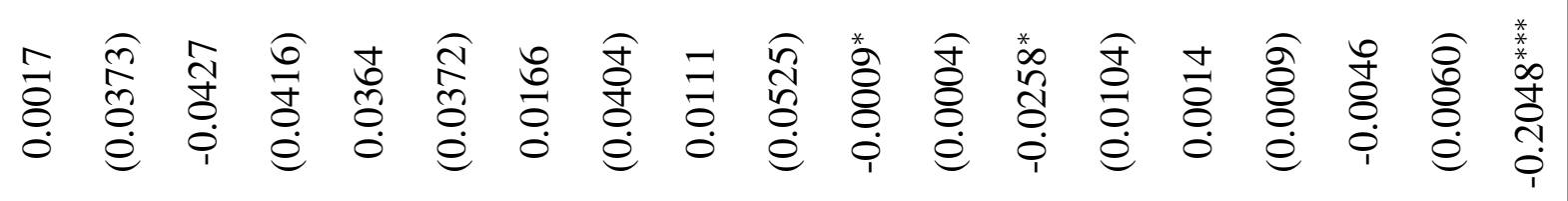

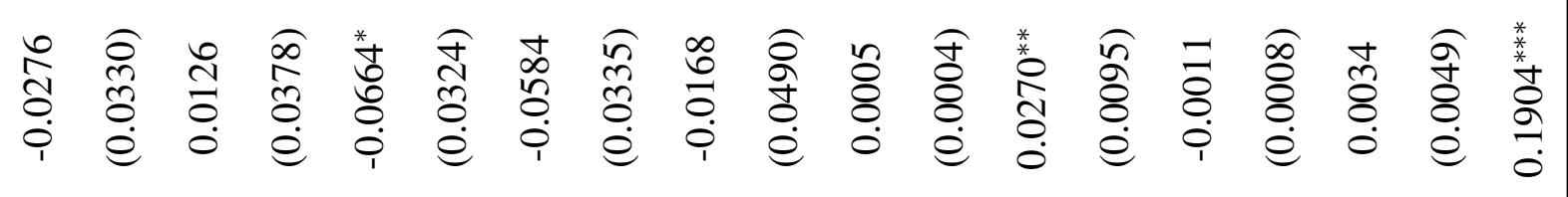

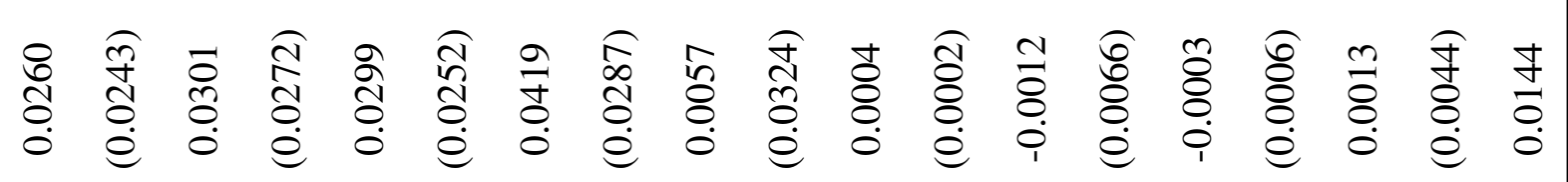

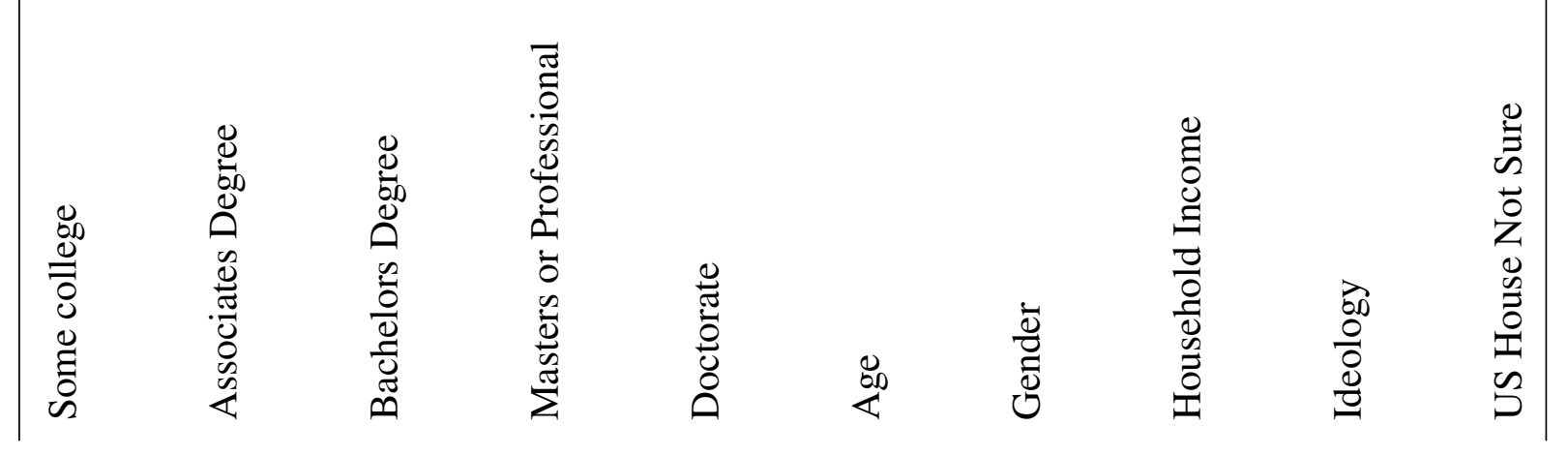




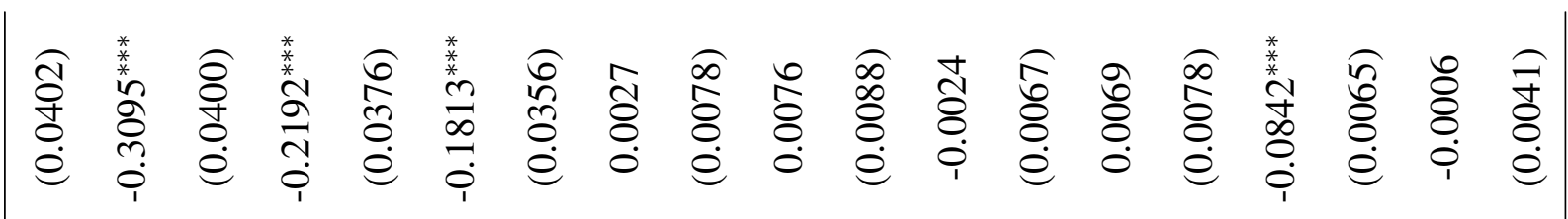

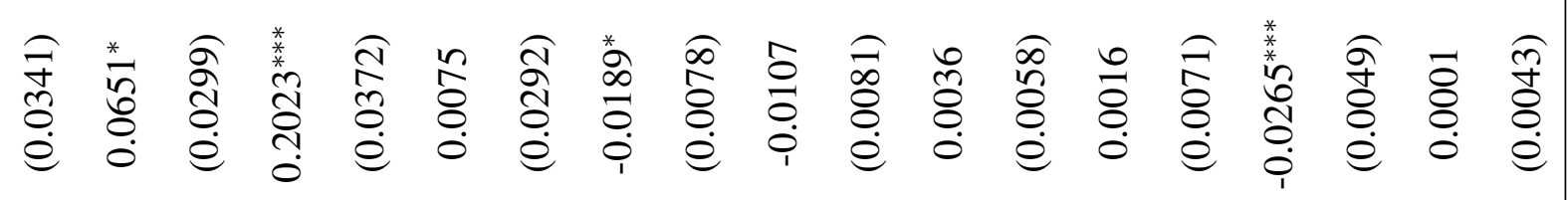

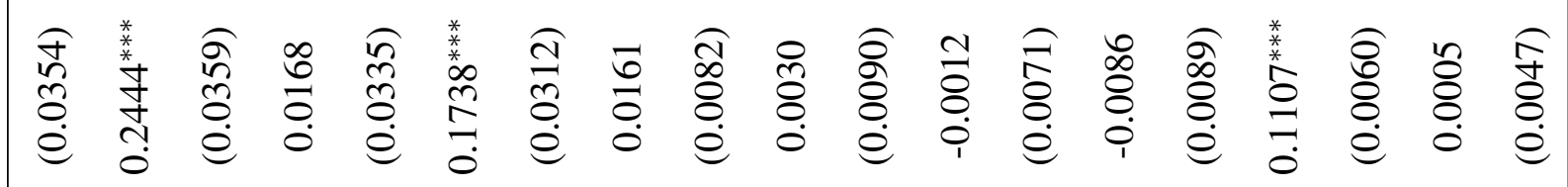

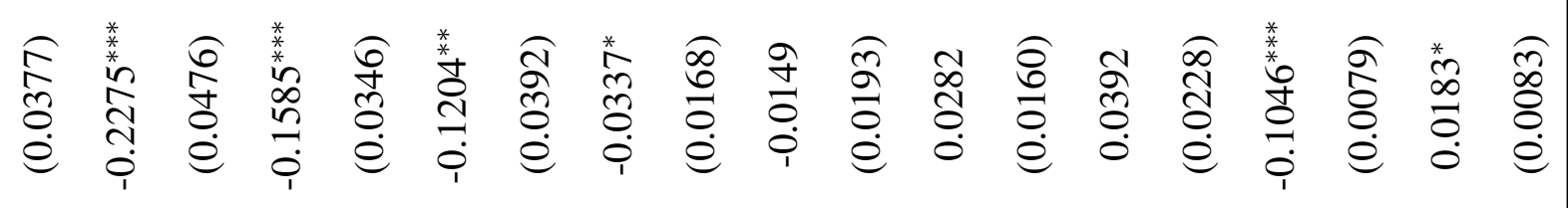

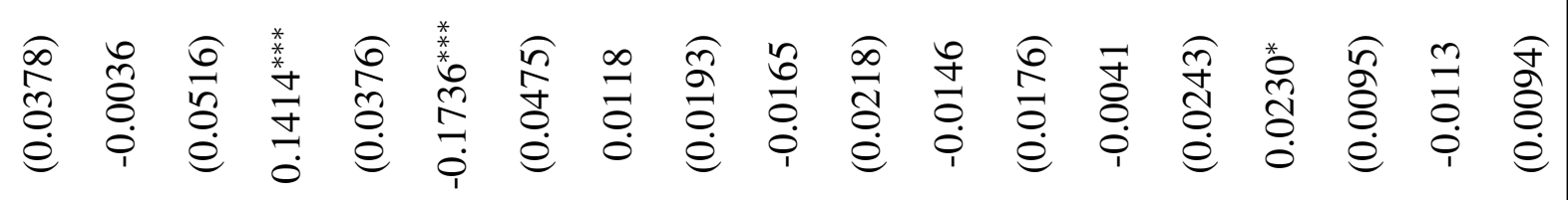

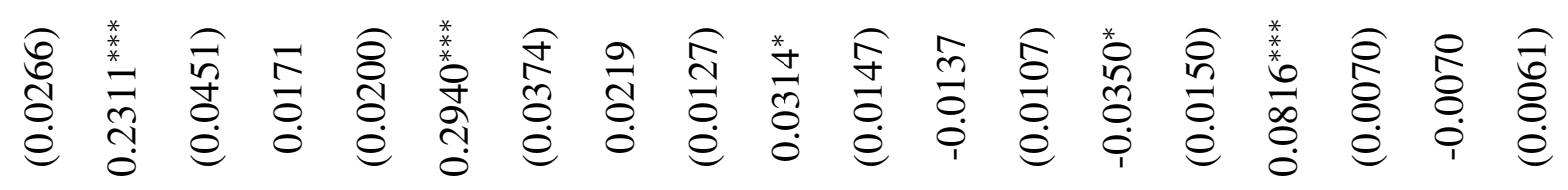

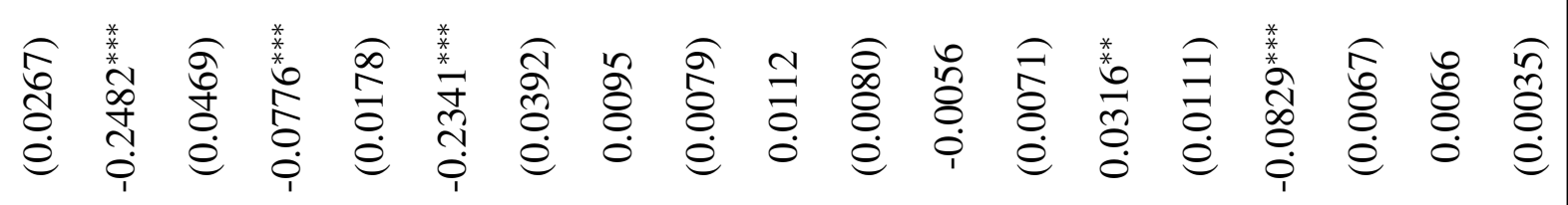

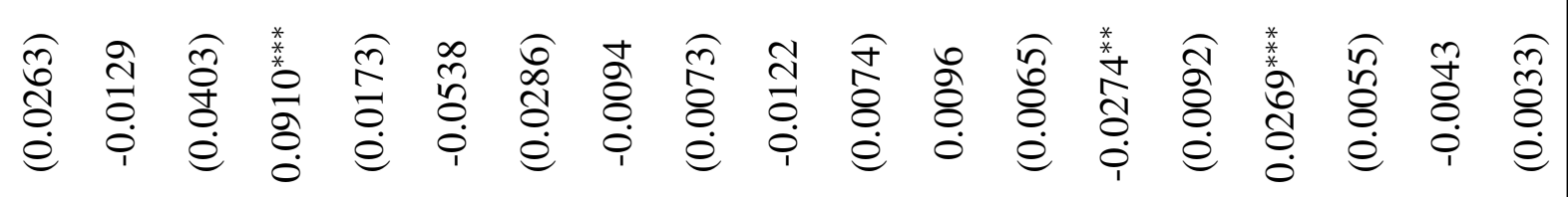

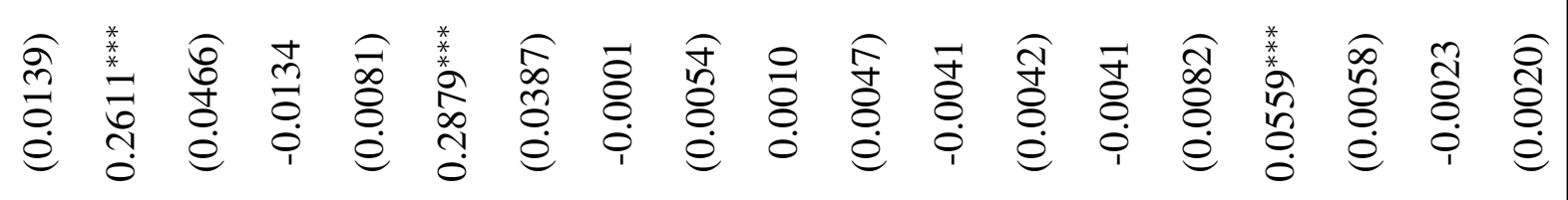

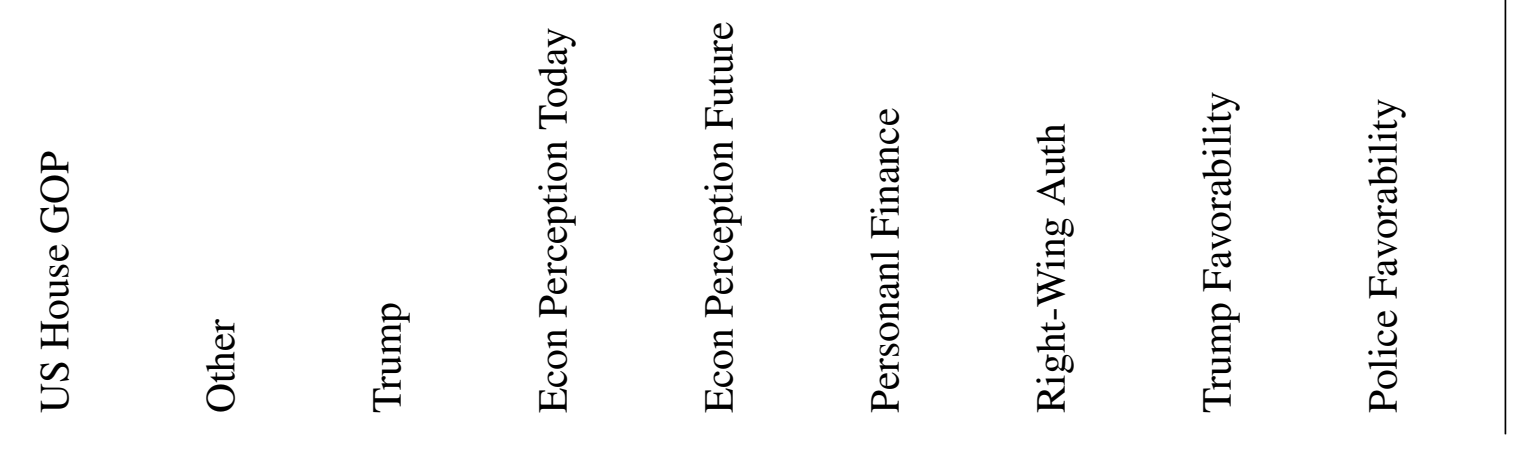




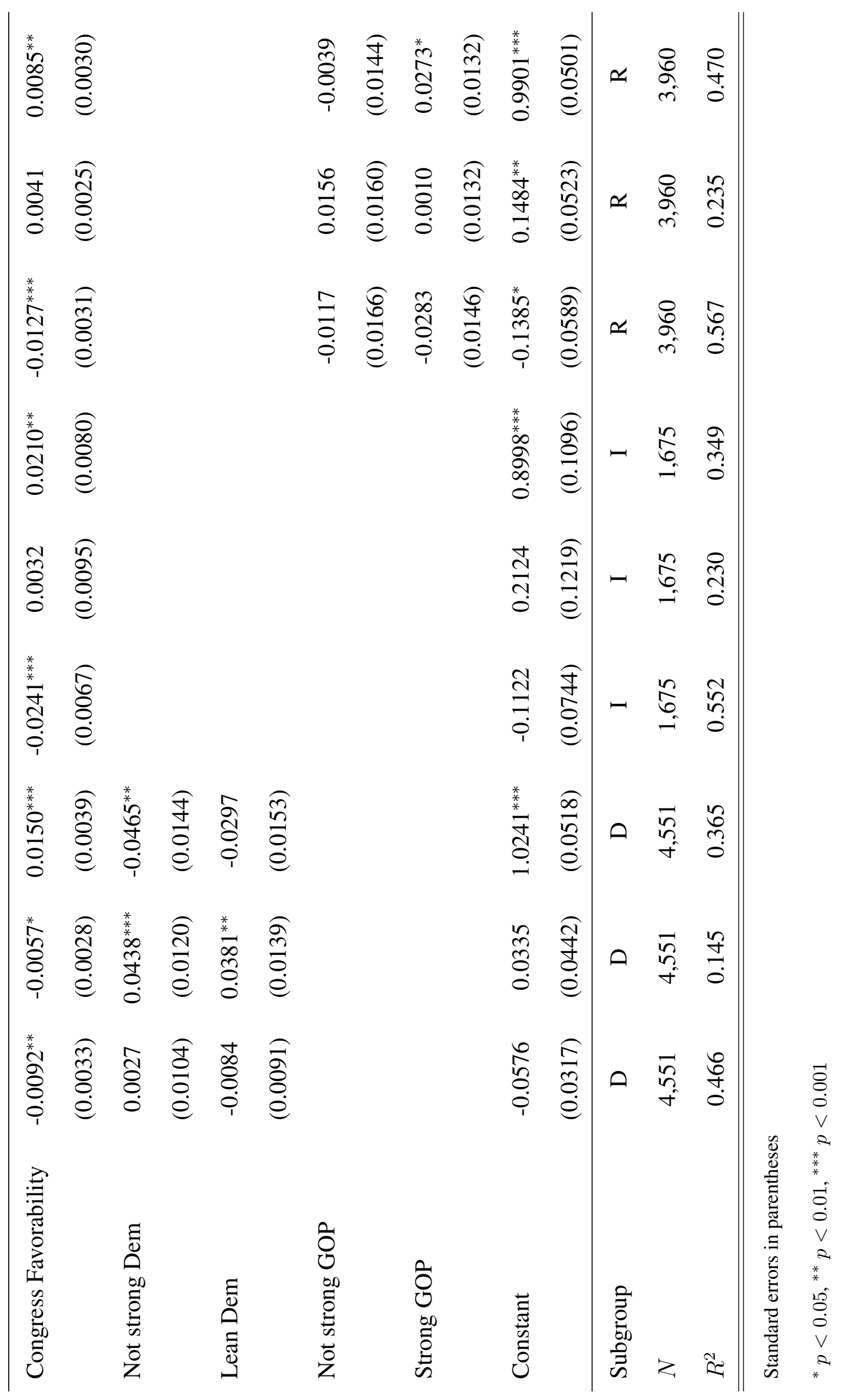


Table A8: Numerical Estimates for Figure 4A Among Not White Not Republicans Under 35

\begin{tabular}{lccc}
\hline \hline & $(1)$ & $(2)$ & $(3)$ \\
& Trump & Neither & Dem \\
\hline Sanders vs. Moderates & $-0.0163^{* *}$ & $-0.0937^{* * *}$ & $0.1100^{* * *}$ \\
& $(0.0059)$ & $(0.0080)$ & $(0.0093)$ \\
Constant & $0.1098^{* * *}$ & $0.2612^{* * *}$ & $0.6289^{* * *}$ \\
& $(0.0020)$ & $(0.0027)$ & $(0.0032)$ \\
\hline$N$ & 18,530 & 18,530 & 18,530 \\
$R^{2}$ & 0.756 & 0.738 & 0.725 \\
\hline \hline
\end{tabular}

Standard errors in parentheses

${ }^{*} p<0.05,{ }^{* *} p<0.01,{ }^{* * *} p<0.001$

Table A9: Numerical Estimates for Figure 4A Among White Not Republicans Under 35

\begin{tabular}{lccc}
\hline \hline & $(1)$ & $(2)$ & $(3)$ \\
& Trump & Neither & Dem \\
\hline Sanders vs. Moderates & $-0.0174^{* * *}$ & $-0.0889^{* * *}$ & $0.1063^{* * *}$ \\
& $(0.0048)$ & $(0.0064)$ & $(0.0074)$ \\
Constant & $0.1474^{* * *}$ & $0.2362^{* * *}$ & $0.6165^{* * *}$ \\
& $(0.0017)$ & $(0.0022)$ & $(0.0026)$ \\
\hline \multirow{2}{*}{$N$} & 23,167 & 23,167 & 23,167 \\
$R^{2}$ & 0.780 & 0.694 & 0.723 \\
\hline \hline
\end{tabular}

Standard errors in parentheses

${ }^{*} p<0.05,{ }^{* *} p<0.01,{ }^{* * *} p<0.001$ 
Table A10: Numerical Estimates for Figure 4A Among Not College Whites Over 35

\begin{tabular}{lccc}
\hline \hline & $(1)$ & $(2)$ & $(3)$ \\
& Trump & Neither & Dem \\
\hline Sanders vs. Moderates & $0.0087^{*}$ & -0.0069 & -0.0018 \\
& $(0.0034)$ & $(0.0041)$ & $(0.0043)$ \\
Constant & $0.5048^{* * *}$ & $0.1550^{* * *}$ & $0.3402^{* * *}$ \\
& $(0.0012)$ & $(0.0014)$ & $(0.0015)$ \\
\hline$N$ & 29,028 & 29,028 & 29,028 \\
$R^{2}$ & 0.925 & 0.783 & 0.871 \\
\hline \hline
\end{tabular}

Standard errors in parentheses

${ }^{*} p<0.05,{ }^{* *} p<0.01,{ }^{* * *} p<0.001$

Table A11: Numerical Estimates for Figure 4A Among All Others

\begin{tabular}{lccc}
\hline \hline & $(1)$ & $(2)$ & $(3)$ \\
& Trump & Neither & Dem \\
\hline Sanders vs. Moderates & $0.0180^{* * *}$ & $-0.0067^{* *}$ & $-0.0113^{* * *}$ \\
& $(0.0021)$ & $(0.0023)$ & $(0.0025)$ \\
Constant & $0.4392^{* * *}$ & $0.1165^{* * *}$ & $0.4443^{* * *}$ \\
& $(0.0007)$ & $(0.0008)$ & $(0.0009)$ \\
\hline$N$ & 109,417 & 109,417 & 109,417 \\
$R^{2}$ & 0.903 & 0.712 & 0.857 \\
\hline \hline
\end{tabular}

Standard errors in parentheses

${ }^{*} p<0.05,{ }^{* *} p<0.01,{ }^{* * *} p<0.001$ 
Table A12: Numerical Estimates for Figure 4B Among Not White Not Republicans Under 35

\begin{tabular}{|c|c|c|c|}
\hline & (1) & (2) & (3) \\
\hline & Trump & Neither & Dem \\
\hline \multirow[t]{2}{*}{ Sanders vs. Moderates } & -0.0076 & $-0.0930^{* * *}$ & $0.1006^{* * *}$ \\
\hline & $(0.0114)$ & $(0.0218)$ & $(0.0225)$ \\
\hline \multirow[t]{2}{*}{ Midwest } & -0.0034 & -0.0344 & 0.0378 \\
\hline & $(0.0194)$ & $(0.0357)$ & $(0.0378)$ \\
\hline \multirow[t]{2}{*}{ South } & -0.0171 & -0.0028 & 0.0199 \\
\hline & $(0.0170)$ & $(0.0293)$ & $(0.0315)$ \\
\hline \multirow[t]{2}{*}{ West } & -0.0321 & 0.0185 & 0.0136 \\
\hline & $(0.0169)$ & $(0.0318)$ & $(0.0333)$ \\
\hline \multirow[t]{2}{*}{ American Indian } & 0.0534 & -0.0644 & 0.0111 \\
\hline & $(0.0491)$ & $(0.0559)$ & $(0.0817)$ \\
\hline \multirow[t]{2}{*}{ Asian } & 0.0165 & -0.0172 & 0.0007 \\
\hline & $(0.0225)$ & $(0.0391)$ & $(0.0376)$ \\
\hline \multirow[t]{2}{*}{ Other } & 0.0265 & -0.0117 & -0.0147 \\
\hline & $(0.0171)$ & $(0.0367)$ & $(0.0365)$ \\
\hline \multirow[t]{2}{*}{ Hispanic } & 0.0202 & -0.0503 & 0.0301 \\
\hline & $(0.0160)$ & $(0.0261)$ & $(0.0277)$ \\
\hline \multirow[t]{2}{*}{ High school } & -0.0283 & 0.0127 & 0.0157 \\
\hline & $(0.0362)$ & $(0.0450)$ & $(0.0485)$ \\
\hline \multirow[t]{2}{*}{ Other post high school } & 0.0180 & -0.0197 & 0.0018 \\
\hline & $(0.0494)$ & $(0.0663)$ & $(0.0640)$ \\
\hline \multirow[t]{2}{*}{ Some college } & -0.0231 & 0.0613 & -0.0382 \\
\hline & $(0.0357)$ & $(0.0463)$ & $(0.0501)$ \\
\hline
\end{tabular}




\begin{tabular}{|c|c|c|c|}
\hline \multirow[t]{2}{*}{ Associates Degree } & -0.0259 & $0.1192^{*}$ & -0.0933 \\
\hline & $(0.0482)$ & $(0.0589)$ & $(0.0628)$ \\
\hline \multirow[t]{2}{*}{ Bachelors Degree } & -0.0387 & 0.0353 & 0.0034 \\
\hline & $(0.0381)$ & $(0.0450)$ & $(0.0492)$ \\
\hline \multirow[t]{2}{*}{ Masters or Professional } & -0.0466 & 0.0461 & 0.0004 \\
\hline & $(0.0495)$ & $(0.0542)$ & $(0.0641)$ \\
\hline \multirow[t]{2}{*}{ Doctorate } & -0.0158 & -0.0030 & 0.0189 \\
\hline & $(0.0682)$ & $(0.0862)$ & $(0.1019)$ \\
\hline \multirow[t]{2}{*}{ Age } & -0.0007 & 0.0024 & -0.0017 \\
\hline & $(0.0013)$ & $(0.0023)$ & $(0.0024)$ \\
\hline \multirow[t]{2}{*}{ Gender } & -0.0081 & 0.0127 & -0.0047 \\
\hline & $(0.0107)$ & $(0.0223)$ & $(0.0225)$ \\
\hline \multirow[t]{2}{*}{ Household Income } & 0.0001 & -0.0021 & 0.0020 \\
\hline & $(0.0012)$ & $(0.0019)$ & $(0.0021)$ \\
\hline \multirow[t]{2}{*}{ Ideology } & 0.0091 & 0.0026 & -0.0118 \\
\hline & $(0.0096)$ & $(0.0114)$ & $(0.0130)$ \\
\hline \multirow[t]{2}{*}{ US House Not Sure } & -0.0157 & $0.1605^{* * *}$ & $-0.1448^{* * *}$ \\
\hline & $(0.0203)$ & $(0.0379)$ & $(0.0404)$ \\
\hline \multirow[t]{2}{*}{ US House GOP } & $0.1906^{* *}$ & -0.0070 & $-0.1835^{*}$ \\
\hline & $(0.0654)$ & $(0.0826)$ & $(0.0786)$ \\
\hline \multirow[t]{2}{*}{ Other } & -0.0111 & $0.0967^{* * *}$ & $-0.0856^{* *}$ \\
\hline & $(0.0123)$ & $(0.0286)$ & $(0.0291)$ \\
\hline \multirow[t]{2}{*}{ Trump } & $0.3962^{* * *}$ & $-0.1615^{* *}$ & $-0.2346^{* * *}$ \\
\hline & $(0.0710)$ & $(0.0587)$ & $(0.0710)$ \\
\hline Econ Perception Today & 0.0029 & -0.0074 & 0.0045 \\
\hline
\end{tabular}




\begin{tabular}{|c|c|c|c|}
\hline & $(0.0082)$ & $(0.0138)$ & $(0.0136)$ \\
\hline \multirow[t]{2}{*}{ Econ Perception Future } & 0.0144 & -0.0287 & 0.0143 \\
\hline & $(0.0083)$ & $(0.0160)$ & $(0.0161)$ \\
\hline \multirow[t]{2}{*}{ Personanl Finance } & $-0.0160^{*}$ & 0.0235 & -0.0075 \\
\hline & $(0.0075)$ & $(0.0130)$ & $(0.0136)$ \\
\hline \multirow[t]{2}{*}{ Right-Wing Auth } & $0.0239^{*}$ & $-0.0466^{*}$ & 0.0227 \\
\hline & $(0.0122)$ & $(0.0216)$ & $(0.0224)$ \\
\hline \multirow[t]{2}{*}{ Trump Favorability } & $0.0453^{* * *}$ & $0.0289^{* *}$ & $-0.0742^{* * *}$ \\
\hline & $(0.0096)$ & $(0.0090)$ & $(0.0112)$ \\
\hline \multirow[t]{2}{*}{ Police Favorability } & -0.0064 & 0.0021 & 0.0043 \\
\hline & $(0.0039)$ & $(0.0064)$ & $(0.0067)$ \\
\hline \multirow[t]{2}{*}{ Congress Favorability } & 0.0035 & $-0.0177^{*}$ & 0.0142 \\
\hline & $(0.0046)$ & $(0.0080)$ & $(0.0083)$ \\
\hline \multirow[t]{2}{*}{ Not strong Dem } & -0.0189 & 0.0267 & -0.0078 \\
\hline & $(0.0158)$ & $(0.0227)$ & $(0.0249)$ \\
\hline \multirow[t]{2}{*}{ Lean Dem } & -0.0050 & 0.0487 & -0.0436 \\
\hline & $(0.0187)$ & $(0.0294)$ & $(0.0329)$ \\
\hline \multirow[t]{2}{*}{ Neither } & -0.0030 & $0.2747^{* * *}$ & $-0.2717^{* * *}$ \\
\hline & $(0.0256)$ & $(0.0461)$ & $(0.0479)$ \\
\hline \multirow[t]{2}{*}{ Constant } & -0.0130 & 0.0196 & $0.9934^{* * *}$ \\
\hline & $(0.0734)$ & $(0.1008)$ & $(0.1083)$ \\
\hline$N$ & 1,264 & 1,264 & 1,264 \\
\hline$R^{2}$ & 0.470 & 0.305 & 0.411 \\
\hline
\end{tabular}

Standard errors in parentheses

${ }^{*} p<0.05,{ }^{* *} p<0.01,{ }^{* * *} p<0.001$ 
Table A13: Numerical Estimates for Figure 4B Among White Not Republicans Under 35

\begin{tabular}{|c|c|c|c|}
\hline & (1) & (2) & (3) \\
\hline & Trump & Neither & Dem \\
\hline \multirow[t]{2}{*}{ Sanders vs. Moderates } & -0.0086 & $-0.0995^{* * *}$ & $0.1081^{* * *}$ \\
\hline & $(0.0164)$ & $(0.0220)$ & $(0.0237)$ \\
\hline \multirow[t]{2}{*}{ Midwest } & 0.0037 & 0.0067 & -0.0104 \\
\hline & $(0.0218)$ & $(0.0287)$ & $(0.0313)$ \\
\hline \multirow[t]{2}{*}{ South } & 0.0025 & -0.0332 & 0.0307 \\
\hline & $(0.0209)$ & $(0.0275)$ & $(0.0302)$ \\
\hline \multirow[t]{2}{*}{ West } & 0.0000 & 0.0614 & -0.0615 \\
\hline & $(0.0220)$ & $(0.0335)$ & $(0.0351)$ \\
\hline \multirow[t]{2}{*}{ High school } & 0.0275 & 0.0132 & -0.0407 \\
\hline & $(0.0289)$ & $(0.0442)$ & $(0.0465)$ \\
\hline \multirow[t]{2}{*}{ Other post high school } & 0.0629 & -0.1128 & 0.0498 \\
\hline & $(0.0589)$ & $(0.0882)$ & $(0.0879)$ \\
\hline \multirow[t]{2}{*}{ Some college } & 0.0485 & -0.0622 & 0.0138 \\
\hline & $(0.0286)$ & $(0.0439)$ & $(0.0471)$ \\
\hline \multirow[t]{2}{*}{ Associates Degree } & 0.0343 & -0.0636 & 0.0293 \\
\hline & $(0.0352)$ & $(0.0513)$ & $(0.0529)$ \\
\hline \multirow[t]{2}{*}{ Bachelors Degree } & 0.0300 & -0.0598 & 0.0298 \\
\hline & $(0.0306)$ & $(0.0456)$ & $(0.0491)$ \\
\hline \multirow[t]{2}{*}{ Masters or Professional } & 0.0028 & -0.0351 & 0.0323 \\
\hline & $(0.0356)$ & $(0.0538)$ & $(0.0582)$ \\
\hline \multirow[t]{2}{*}{ Doctorate } & 0.0699 & -0.1157 & 0.0458 \\
\hline & $(0.0965)$ & $(0.0724)$ & $(0.1070)$ \\
\hline
\end{tabular}




\begin{tabular}{|c|c|c|c|}
\hline \multirow[t]{2}{*}{ Age } & 0.0010 & -0.0005 & -0.0005 \\
\hline & $(0.0015)$ & $(0.0023)$ & $(0.0024)$ \\
\hline \multirow[t]{2}{*}{ Gender } & -0.0066 & 0.0315 & -0.0249 \\
\hline & $(0.0150)$ & $(0.0224)$ & $(0.0228)$ \\
\hline \multirow[t]{2}{*}{ Household Income } & 0.0018 & 0.0006 & -0.0024 \\
\hline & $(0.0012)$ & $(0.0017)$ & $(0.0017)$ \\
\hline \multirow[t]{2}{*}{ Ideology } & -0.0083 & 0.0089 & -0.0006 \\
\hline & $(0.0105)$ & $(0.0152)$ & $(0.0154)$ \\
\hline \multirow[t]{2}{*}{ US House Not Sure } & 0.0133 & $0.2135^{* * *}$ & $-0.2268^{* * *}$ \\
\hline & $(0.0217)$ & $(0.0332)$ & $(0.0352)$ \\
\hline \multirow[t]{2}{*}{ US House GOP } & $0.2283^{* * *}$ & -0.0473 & $-0.1810^{* *}$ \\
\hline & $(0.0525)$ & $(0.0534)$ & $(0.0593)$ \\
\hline \multirow[t]{2}{*}{ Other } & -0.0110 & $0.1525^{* * *}$ & $-0.1415^{* * *}$ \\
\hline & $(0.0161)$ & $(0.0280)$ & $(0.0299)$ \\
\hline \multirow[t]{2}{*}{ Trump } & $0.2505^{* * *}$ & -0.0906 & $-0.1599^{* *}$ \\
\hline & $(0.0443)$ & $(0.0494)$ & $(0.0507)$ \\
\hline \multirow[t]{2}{*}{ Econ Perception Today } & 0.0047 & -0.0191 & 0.0144 \\
\hline & (0.0114) & $(0.0158)$ & $(0.0158)$ \\
\hline \multirow[t]{2}{*}{ Econ Perception Future } & 0.0079 & 0.0071 & -0.0150 \\
\hline & $(0.0115)$ & $(0.0158)$ & $(0.0168)$ \\
\hline \multirow[t]{2}{*}{ Personanl Finance } & 0.0002 & 0.0069 & -0.0071 \\
\hline & $(0.0108)$ & $(0.0150)$ & $(0.0157)$ \\
\hline \multirow[t]{2}{*}{ Right-Wing Auth } & $-0.0329^{*}$ & -0.0148 & $0.0477^{*}$ \\
\hline & $(0.0149)$ & $(0.0203)$ & $(0.0209)$ \\
\hline Trump Favorability & $0.0669^{* * *}$ & $0.0296^{* *}$ & $-0.0965^{* * *}$ \\
\hline
\end{tabular}




\begin{tabular}{lccc}
\hline & $(0.0086)$ & $(0.0108)$ & $(0.0107)$ \\
Police Favorability & -0.0051 & 0.0021 & 0.0030 \\
& $(0.0050)$ & $(0.0072)$ & $(0.0073)$ \\
Congress Favorability & $-0.0163^{* *}$ & -0.0029 & $0.0192^{*}$ \\
& $(0.0060)$ & $(0.0079)$ & $(0.0075)$ \\
Not strong Dem & -0.0198 & 0.0460 & -0.0262 \\
& $(0.0175)$ & $(0.0266)$ & $(0.0293)$ \\
Lean Dem & 0.0018 & -0.0026 & 0.0008 \\
& $(0.0241)$ & $(0.0280)$ & $(0.0336)$ \\
Neither & -0.0058 & $0.1428^{* * *}$ & $-0.1370^{* *}$ \\
& $(0.0289)$ & $(0.0394)$ & $(0.0430)$ \\
Constant & -0.0524 & -0.0115 & $1.0639^{* * *}$ \\
& $(0.0701)$ & $(0.0939)$ & $(0.0998)$ \\
\hline$N$ & 1,639 & 1,639 & 1,639 \\
$R^{2}$ & 0.444 & 0.285 & 0.464 \\
\hline \hline
\end{tabular}

Standard errors in parentheses

${ }^{*} p<0.05,{ }^{* *} p<0.01,{ }^{* * *} p<0.001$

Table A14: Numerical Estimates for Figure 4B Among Not College Whites Over 35

\begin{tabular}{lccc}
\hline \hline & $(1)$ & $(2)$ & $(3)$ \\
& Trump & Neither & Dem \\
\hline Sanders vs. Moderates & $0.0341^{* *}$ & $-0.0304^{*}$ & -0.0037 \\
& $(0.0109)$ & $(0.0127)$ & $(0.0109)$ \\
Midwest & 0.0085 & 0.0249 & $-0.0334^{*}$ \\
& $(0.0149)$ & $(0.0181)$ & $(0.0155)$ \\
\hline
\end{tabular}




\begin{tabular}{|c|c|c|c|}
\hline \multirow[t]{2}{*}{ South } & 0.0057 & 0.0311 & $-0.0369^{* *}$ \\
\hline & $(0.0131)$ & $(0.0164)$ & $(0.0143)$ \\
\hline \multirow[t]{2}{*}{ West } & 0.0029 & 0.0154 & -0.0183 \\
\hline & $(0.0164)$ & $(0.0195)$ & $(0.0186)$ \\
\hline \multirow[t]{2}{*}{ High school } & 0.0482 & $-0.0768^{*}$ & 0.0287 \\
\hline & $(0.0256)$ & $(0.0314)$ & $(0.0304)$ \\
\hline \multirow[t]{2}{*}{ Other post high school } & 0.0435 & $-0.1050^{* *}$ & 0.0615 \\
\hline & $(0.0287)$ & $(0.0335)$ & $(0.0324)$ \\
\hline \multirow[t]{2}{*}{ Some college } & $0.0585^{*}$ & $-0.1087^{* * *}$ & 0.0502 \\
\hline & $(0.0264)$ & $(0.0315)$ & $(0.0307)$ \\
\hline \multirow[t]{2}{*}{ Associates Degree } & 0.0324 & -0.0602 & 0.0278 \\
\hline & $(0.0273)$ & $(0.0330)$ & $(0.0319)$ \\
\hline \multirow[t]{2}{*}{ Age } & 0.0004 & -0.0005 & 0.0001 \\
\hline & $(0.0004)$ & $(0.0005)$ & $(0.0005)$ \\
\hline \multirow[t]{2}{*}{ Gender } & -0.0170 & $0.0246^{*}$ & -0.0077 \\
\hline & $(0.0098)$ & $(0.0122)$ & $(0.0104)$ \\
\hline \multirow[t]{2}{*}{ Household Income } & -0.0006 & 0.0019 & -0.0013 \\
\hline & $(0.0009)$ & $(0.0012)$ & $(0.0010)$ \\
\hline \multirow[t]{2}{*}{ Ideology } & -0.0088 & 0.0070 & 0.0017 \\
\hline & $(0.0068)$ & $(0.0079)$ & $(0.0070)$ \\
\hline \multirow[t]{2}{*}{ US House Not Sure } & $0.0706^{* *}$ & $0.2643^{* * *}$ & $-0.3349^{* * *}$ \\
\hline & $(0.0251)$ & $(0.0379)$ & $(0.0377)$ \\
\hline \multirow[t]{2}{*}{ US House GOP } & $0.2856^{* * *}$ & 0.0730 & $-0.3586^{* * *}$ \\
\hline & $(0.0357)$ & $(0.0425)$ & $(0.0415)$ \\
\hline Other & $-0.0643^{* *}$ & $0.2189^{* * *}$ & $-0.1545^{* * *}$ \\
\hline
\end{tabular}




\begin{tabular}{|c|c|c|c|}
\hline & $(0.0201)$ & $(0.0338)$ & $(0.0308)$ \\
\hline \multirow[t]{2}{*}{ Trump } & $0.1789^{* * *}$ & $-0.0898^{*}$ & $-0.0891^{* *}$ \\
\hline & $(0.0306)$ & $(0.0355)$ & $(0.0305)$ \\
\hline \multirow[t]{2}{*}{ Econ Perception Today } & 0.0095 & -0.0197 & 0.0102 \\
\hline & $(0.0085)$ & $(0.0107)$ & $(0.0094)$ \\
\hline \multirow[t]{2}{*}{ Econ Perception Future } & 0.0084 & -0.0195 & 0.0111 \\
\hline & $(0.0086)$ & $(0.0113)$ & $(0.0096)$ \\
\hline \multirow[t]{2}{*}{ Personanl Finance } & -0.0042 & -0.0010 & 0.0052 \\
\hline & $(0.0065)$ & $(0.0085)$ & $(0.0081)$ \\
\hline \multirow[t]{2}{*}{ Right-Wing Auth } & -0.0026 & -0.0177 & $0.0203^{*}$ \\
\hline & $(0.0083)$ & $(0.0098)$ & $(0.0096)$ \\
\hline \multirow[t]{2}{*}{ Trump Favorability } & $0.0977^{* * *}$ & -0.0089 & $-0.0889^{* * *}$ \\
\hline & $(0.0065)$ & $(0.0073)$ & $(0.0071)$ \\
\hline \multirow[t]{2}{*}{ Police Favorability } & 0.0063 & $-0.0110^{*}$ & 0.0047 \\
\hline & $(0.0041)$ & $(0.0056)$ & $(0.0050)$ \\
\hline \multirow[t]{2}{*}{ Congress Favorability } & $-0.0070^{*}$ & 0.0043 & 0.0028 \\
\hline & $(0.0031)$ & $(0.0033)$ & $(0.0032)$ \\
\hline \multirow[t]{2}{*}{ Not strong Dem } & $-0.0377^{*}$ & $0.0567^{*}$ & -0.0190 \\
\hline & $(0.0146)$ & $(0.0260)$ & $(0.0258)$ \\
\hline \multirow[t]{2}{*}{ Lean Dem } & -0.0132 & -0.0130 & 0.0262 \\
\hline & $(0.0180)$ & $(0.0269)$ & $(0.0289)$ \\
\hline \multirow[t]{2}{*}{ Neither } & -0.0269 & $0.1481^{* * *}$ & $-0.1212^{* *}$ \\
\hline & $(0.0252)$ & $(0.0420)$ & $(0.0389)$ \\
\hline \multirow[t]{2}{*}{ Lean GOP } & 0.0025 & 0.0709 & -0.0734 \\
\hline & $(0.0326)$ & $(0.0407)$ & $(0.0376)$ \\
\hline
\end{tabular}




\begin{tabular}{lccc}
\hline Not strong GOP & 0.0185 & $0.0985^{*}$ & $-0.1170^{* *}$ \\
& $(0.0283)$ & $(0.0391)$ & $(0.0355)$ \\
Strong GOP & -0.0079 & 0.0607 & -0.0527 \\
& $(0.0287)$ & $(0.0382)$ & $(0.0364)$ \\
Constant & $-0.1839^{* * *}$ & $0.1830^{* *}$ & $1.0009^{* * *}$ \\
& $(0.0502)$ & $(0.0593)$ & $(0.0504)$ \\
\hline$N$ & 2,604 & 2,604 & 2,604 \\
$R^{2}$ & 0.822 & 0.384 & 0.755 \\
\hline \hline
\end{tabular}

Standard errors in parentheses

${ }^{*} p<0.05,{ }^{* *} p<0.01,{ }^{* * *} p<0.001$

Table A15: Numerical Estimates for Figure 4B Among All Others

\begin{tabular}{lccc}
\hline \hline & $(1)$ & $(2)$ & $(3)$ \\
& Trump & Neither & Dem \\
\hline Sanders vs. Moderates & $0.0246^{*}$ & $-0.0336^{* *}$ & 0.0090 \\
& $(0.0118)$ & $(0.0106)$ & $(0.0127)$ \\
Midwest & -0.0098 & 0.0026 & 0.0072 \\
South & $(0.0130)$ & $(0.0139)$ & $(0.0151)$ \\
& -0.0147 & 0.0127 & 0.0020 \\
West & $(0.0117)$ & $(0.0134)$ & $(0.0147)$ \\
& -0.0014 & 0.0058 & -0.0044 \\
Black & $(0.0144)$ & $(0.0153)$ & $(0.0166)$ \\
& $-0.0413^{* *}$ & 0.0303 & 0.0110 \\
& $(0.0143)$ & $(0.0166)$ & $(0.0181)$ \\
& -0.0263 & 0.0485 & -0.0222 \\
\hline
\end{tabular}




\begin{tabular}{|c|c|c|c|}
\hline & $(0.0359)$ & $(0.0398)$ & $(0.0324)$ \\
\hline \multirow[t]{2}{*}{ Asian } & -0.0050 & -0.0027 & 0.0077 \\
\hline & $(0.0195)$ & $(0.0225)$ & $(0.0249)$ \\
\hline \multirow[t]{2}{*}{ Other } & -0.0230 & 0.0082 & 0.0148 \\
\hline & $(0.0199)$ & $(0.0251)$ & $(0.0243)$ \\
\hline \multirow[t]{2}{*}{ Hispanic } & 0.0073 & 0.0191 & -0.0264 \\
\hline & $(0.0173)$ & $(0.0167)$ & $(0.0193)$ \\
\hline \multirow[t]{2}{*}{ High school } & -0.0111 & -0.0352 & 0.0463 \\
\hline & $(0.0314)$ & $(0.0376)$ & $(0.0302)$ \\
\hline \multirow[t]{2}{*}{ Other post high school } & 0.0096 & -0.0746 & 0.0650 \\
\hline & $(0.0370)$ & $(0.0480)$ & $(0.0430)$ \\
\hline \multirow[t]{2}{*}{ Some college } & 0.0106 & -0.0304 & 0.0198 \\
\hline & $(0.0309)$ & $(0.0378)$ & $(0.0298)$ \\
\hline \multirow[t]{2}{*}{ Associates Degree } & 0.0218 & -0.0357 & 0.0139 \\
\hline & $(0.0332)$ & $(0.0466)$ & $(0.0392)$ \\
\hline \multirow[t]{2}{*}{ Bachelors Degree } & 0.0074 & -0.0567 & 0.0493 \\
\hline & $(0.0299)$ & $(0.0370)$ & $(0.0286)$ \\
\hline \multirow[t]{2}{*}{ Masters or Professional } & 0.0237 & -0.0569 & 0.0331 \\
\hline & $(0.0313)$ & $(0.0383)$ & $(0.0304)$ \\
\hline \multirow[t]{2}{*}{ Doctorate } & -0.0240 & -0.0230 & 0.0470 \\
\hline & $(0.0362)$ & $(0.0452)$ & $(0.0392)$ \\
\hline \multirow[t]{2}{*}{ Age } & -0.0000 & 0.0002 & -0.0001 \\
\hline & $(0.0003)$ & $(0.0004)$ & $(0.0004)$ \\
\hline \multirow[t]{2}{*}{ Gender } & 0.0122 & 0.0026 & -0.0148 \\
\hline & $(0.0086)$ & $(0.0101)$ & $(0.0102)$ \\
\hline
\end{tabular}




\begin{tabular}{|c|c|c|c|}
\hline \multirow[t]{2}{*}{ Household Income } & -0.0008 & -0.0009 & 0.0018 \\
\hline & $(0.0008)$ & $(0.0009)$ & $(0.0009)$ \\
\hline \multirow[t]{2}{*}{ Ideology } & -0.0003 & 0.0049 & -0.0046 \\
\hline & $(0.0052)$ & $(0.0051)$ & $(0.0061)$ \\
\hline \multirow[t]{2}{*}{ US House Not Sure } & -0.0120 & $0.2972^{* * *}$ & $-0.2852^{* * *}$ \\
\hline & $(0.0223)$ & $(0.0299)$ & $(0.0317)$ \\
\hline \multirow[t]{2}{*}{ US House GOP } & $0.2229^{* * *}$ & 0.0511 & $-0.2740^{* * *}$ \\
\hline & $(0.0307)$ & $(0.0282)$ & $(0.0340)$ \\
\hline \multirow[t]{2}{*}{ Other } & 0.0309 & $0.1080^{* * *}$ & $-0.1389^{* * *}$ \\
\hline & $(0.0178)$ & $(0.0257)$ & $(0.0259)$ \\
\hline \multirow[t]{2}{*}{ Trump } & $0.2388^{* * *}$ & $-0.0572^{*}$ & $-0.1816^{* * *}$ \\
\hline & $(0.0273)$ & $(0.0254)$ & $(0.0295)$ \\
\hline \multirow[t]{2}{*}{ Econ Perception Today } & 0.0130 & 0.0019 & -0.0149 \\
\hline & $(0.0071)$ & $(0.0084)$ & $(0.0085)$ \\
\hline \multirow[t]{2}{*}{ Econ Perception Future } & 0.0007 & -0.0130 & 0.0123 \\
\hline & $(0.0074)$ & $(0.0085)$ & $(0.0091)$ \\
\hline \multirow[t]{2}{*}{ Personanl Finance } & -0.0038 & 0.0016 & 0.0022 \\
\hline & $(0.0061)$ & $(0.0072)$ & $(0.0077)$ \\
\hline \multirow[t]{2}{*}{ Right-Wing Auth } & -0.0097 & -0.0064 & 0.0160 \\
\hline & $(0.0087)$ & $(0.0087)$ & $(0.0100)$ \\
\hline \multirow[t]{2}{*}{ Trump Favorability } & $0.0885^{* * *}$ & -0.0019 & $-0.0866^{* * *}$ \\
\hline & $(0.0054)$ & $(0.0050)$ & $(0.0059)$ \\
\hline \multirow[t]{2}{*}{ Police Favorability } & -0.0029 & -0.0060 & $0.0089^{*}$ \\
\hline & $(0.0033)$ & $(0.0042)$ & $(0.0041)$ \\
\hline Congress Favorability & $-0.0214^{* * *}$ & 0.0033 & $0.0180^{* * *}$ \\
\hline
\end{tabular}




\begin{tabular}{|c|c|c|c|}
\hline & $(0.0034)$ & $(0.0029)$ & $(0.0037)$ \\
\hline \multirow[t]{2}{*}{ Not strong Dem } & -0.0041 & $0.0564^{* *}$ & $-0.0522^{*}$ \\
\hline & $(0.0203)$ & $(0.0204)$ & $(0.0260)$ \\
\hline \multirow[t]{2}{*}{ Lean Dem } & $-0.0300^{*}$ & $0.0482^{*}$ & -0.0182 \\
\hline & $(0.0126)$ & $(0.0242)$ & $(0.0241)$ \\
\hline \multirow[t]{2}{*}{ Neither } & -0.0182 & $0.1177^{* * *}$ & $-0.0995^{* *}$ \\
\hline & $(0.0231)$ & $(0.0304)$ & $(0.0311)$ \\
\hline \multirow[t]{2}{*}{ Lean GOP } & $0.0834^{* *}$ & 0.0200 & $-0.1034^{* * *}$ \\
\hline & $(0.0275)$ & $(0.0282)$ & $(0.0308)$ \\
\hline \multirow[t]{2}{*}{ Not strong GOP } & 0.0380 & 0.0409 & $-0.0789^{* *}$ \\
\hline & $(0.0251)$ & $(0.0277)$ & $(0.0300)$ \\
\hline \multirow[t]{2}{*}{ Strong GOP } & 0.0424 & 0.0112 & -0.0536 \\
\hline & $(0.0271)$ & $(0.0269)$ & $(0.0313)$ \\
\hline \multirow[t]{2}{*}{ Constant } & -0.0438 & 0.0824 & $0.9614^{* * *}$ \\
\hline & $(0.0455)$ & $(0.0492)$ & $(0.0476)$ \\
\hline$N$ & 4,679 & 4,679 & 4,679 \\
\hline$R^{2}$ & 0.760 & 0.243 & 0.696 \\
\hline
\end{tabular}

Standard errors in parentheses

${ }^{*} p<0.05,{ }^{* *} p<0.01,{ }^{* * *} p<0.001$ 


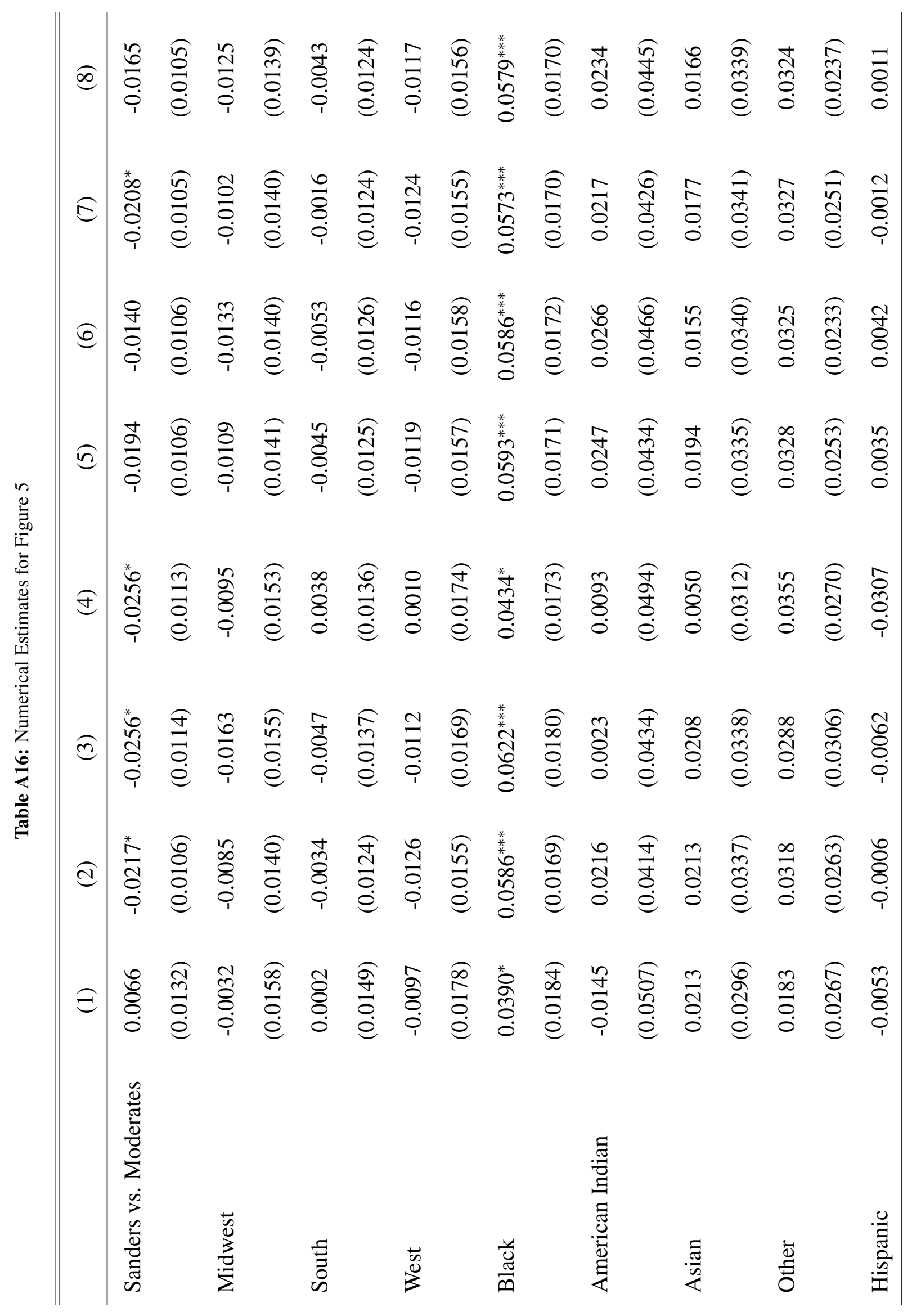




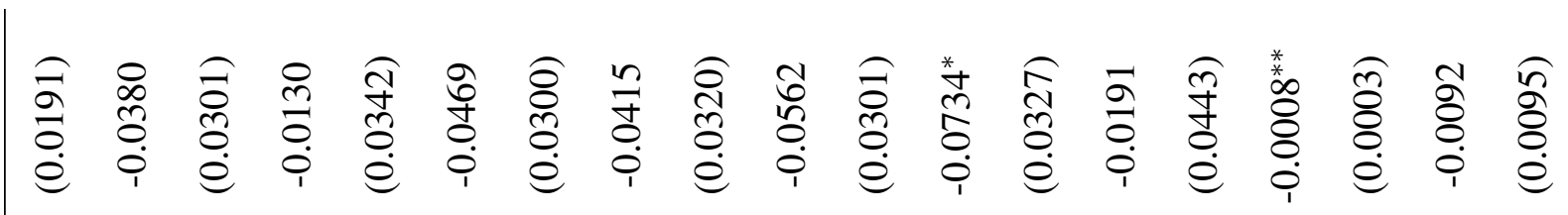

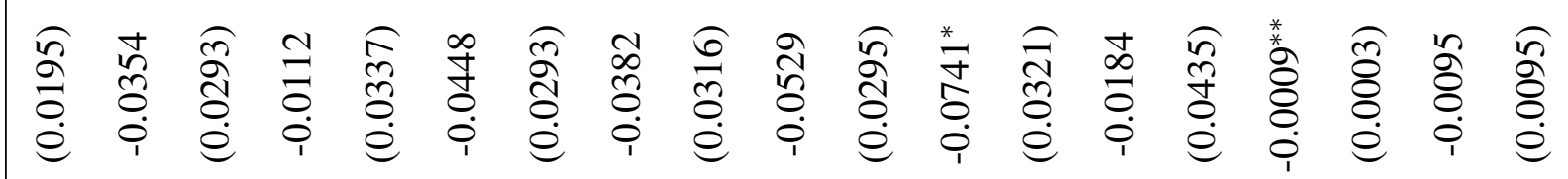

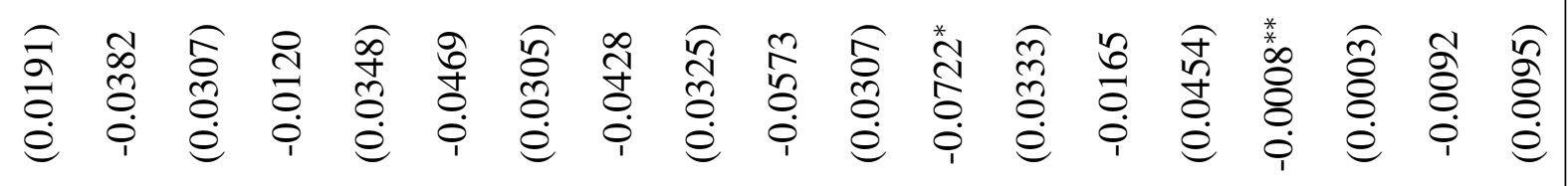

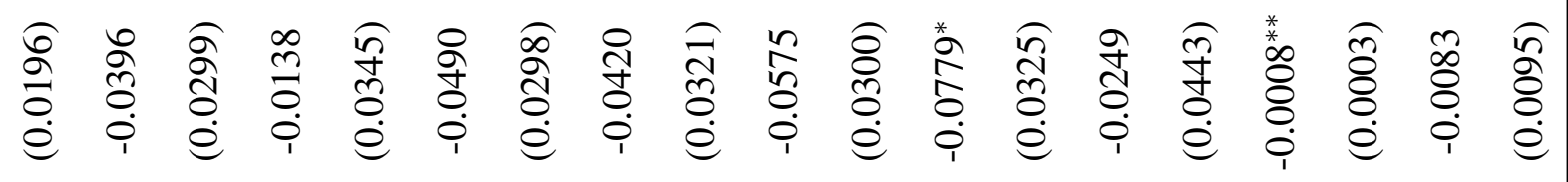

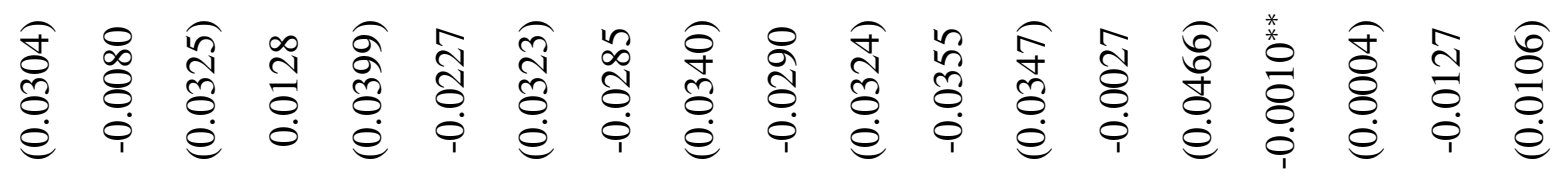

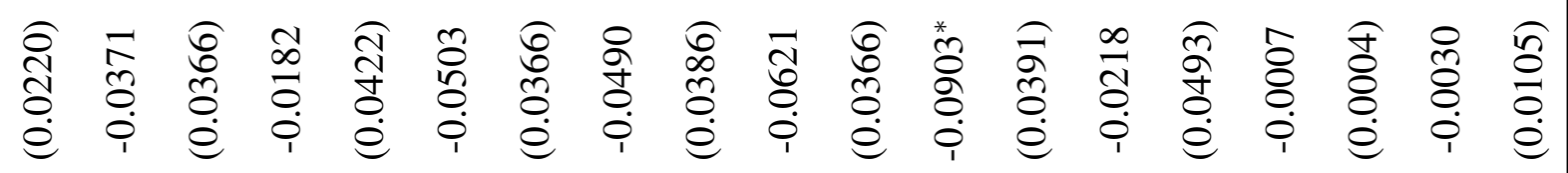

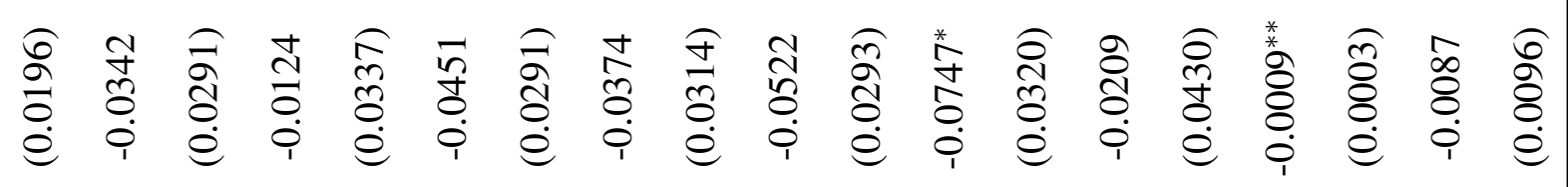

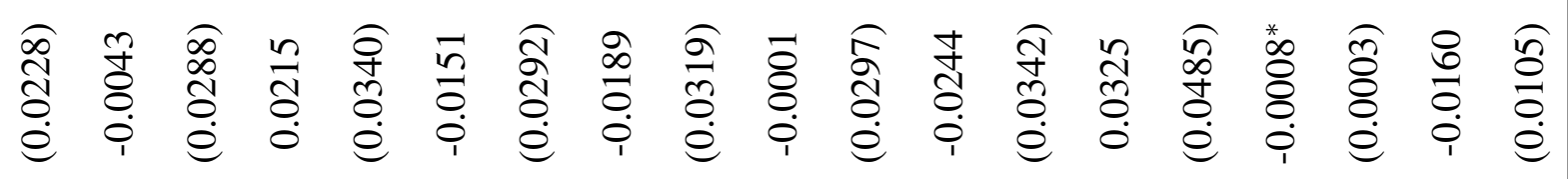

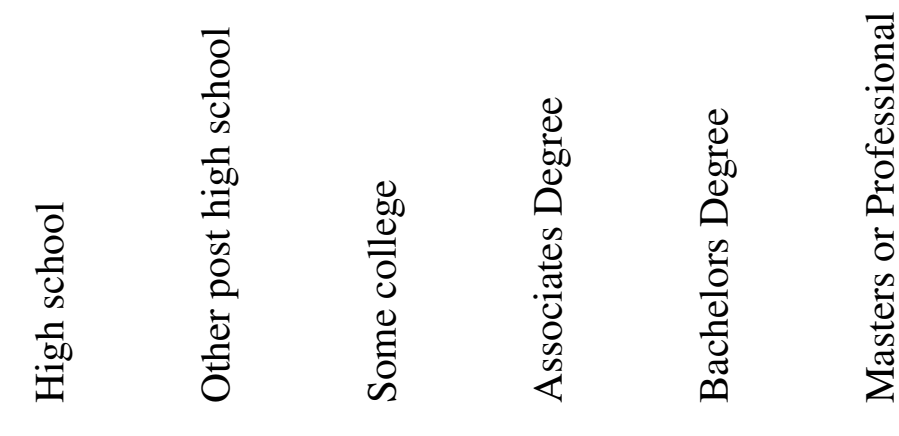

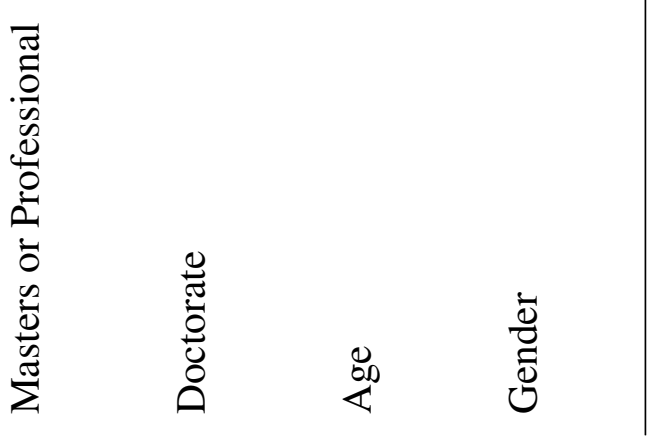




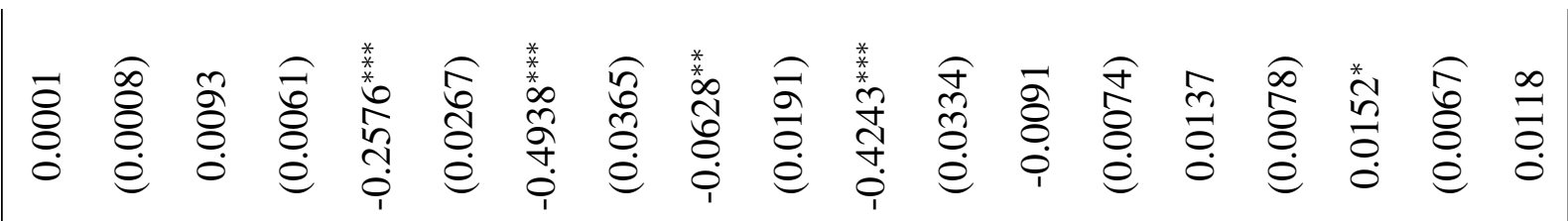

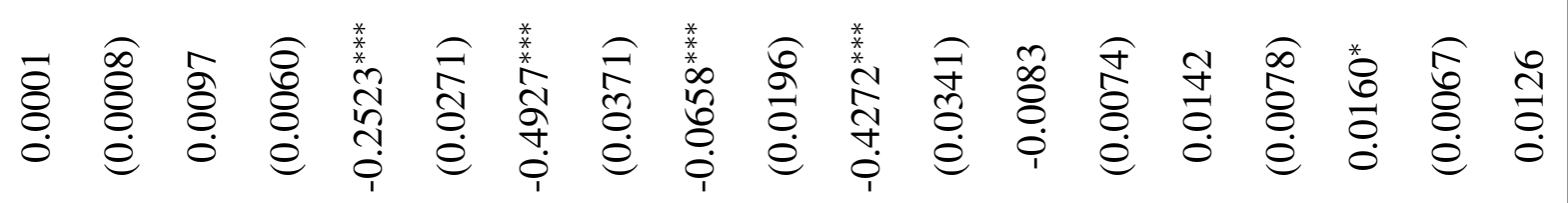

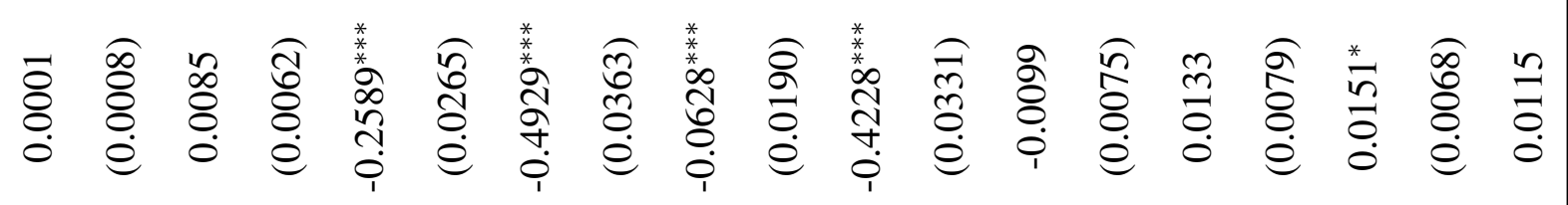

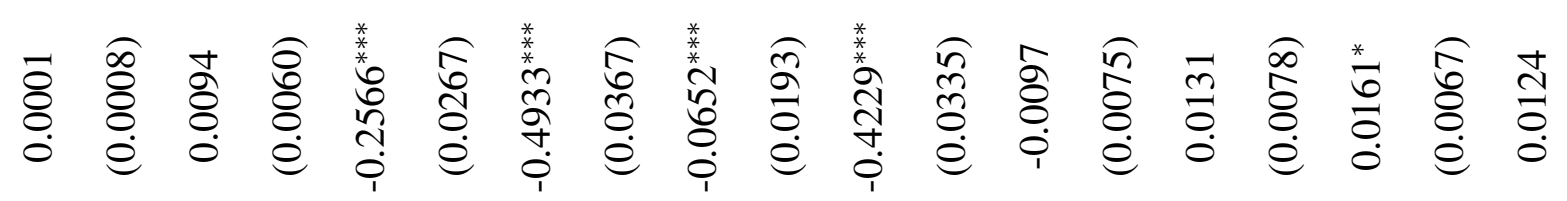

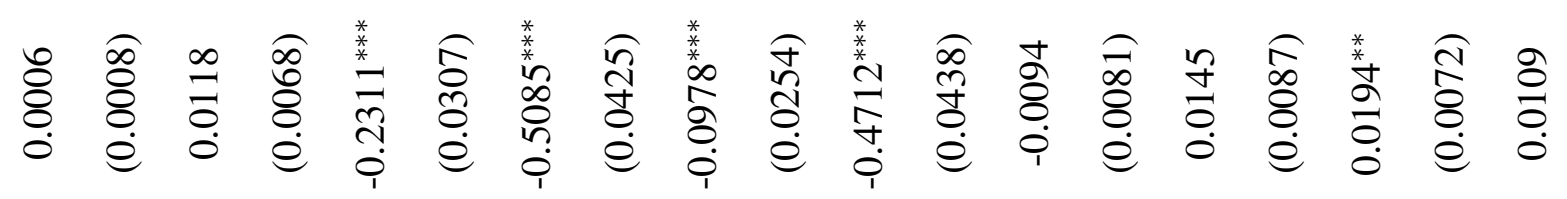

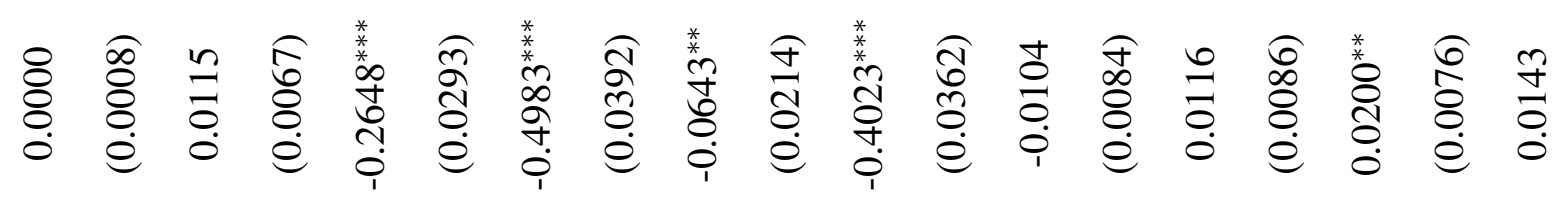

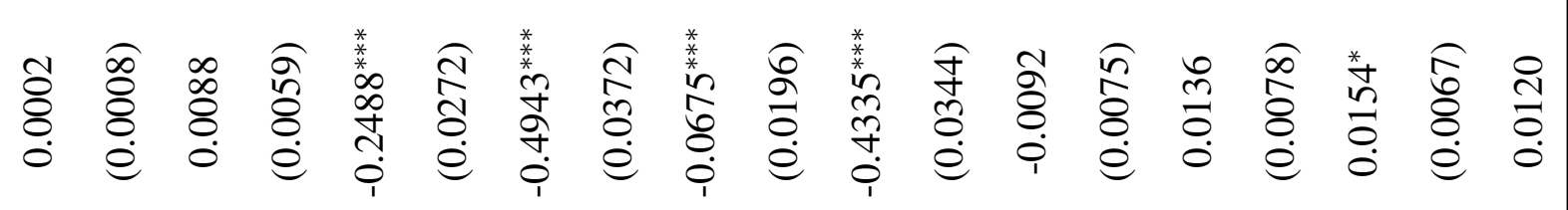

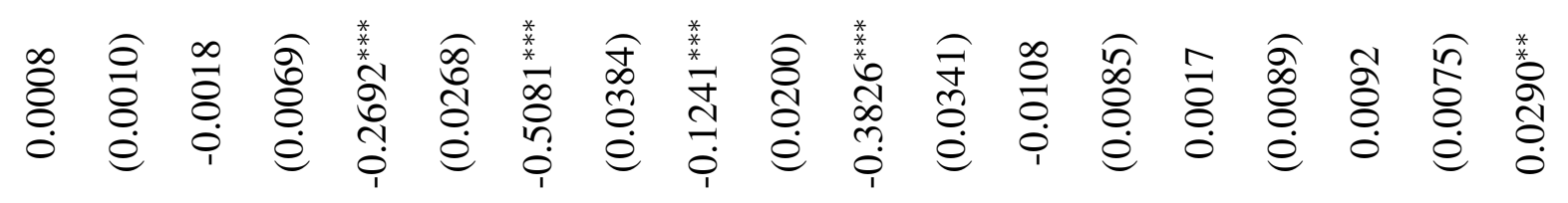

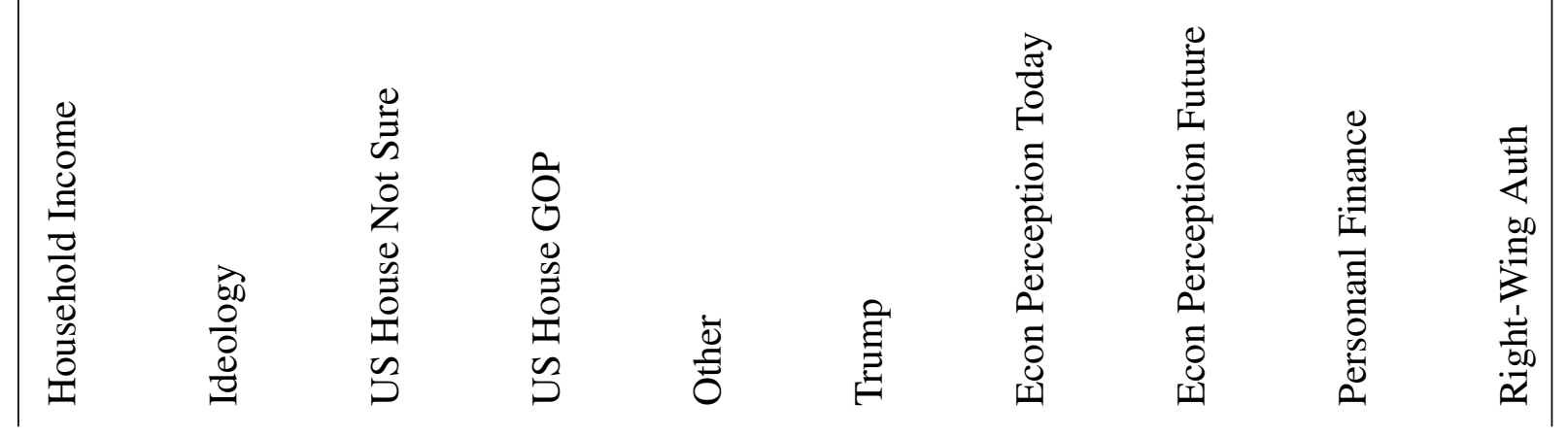




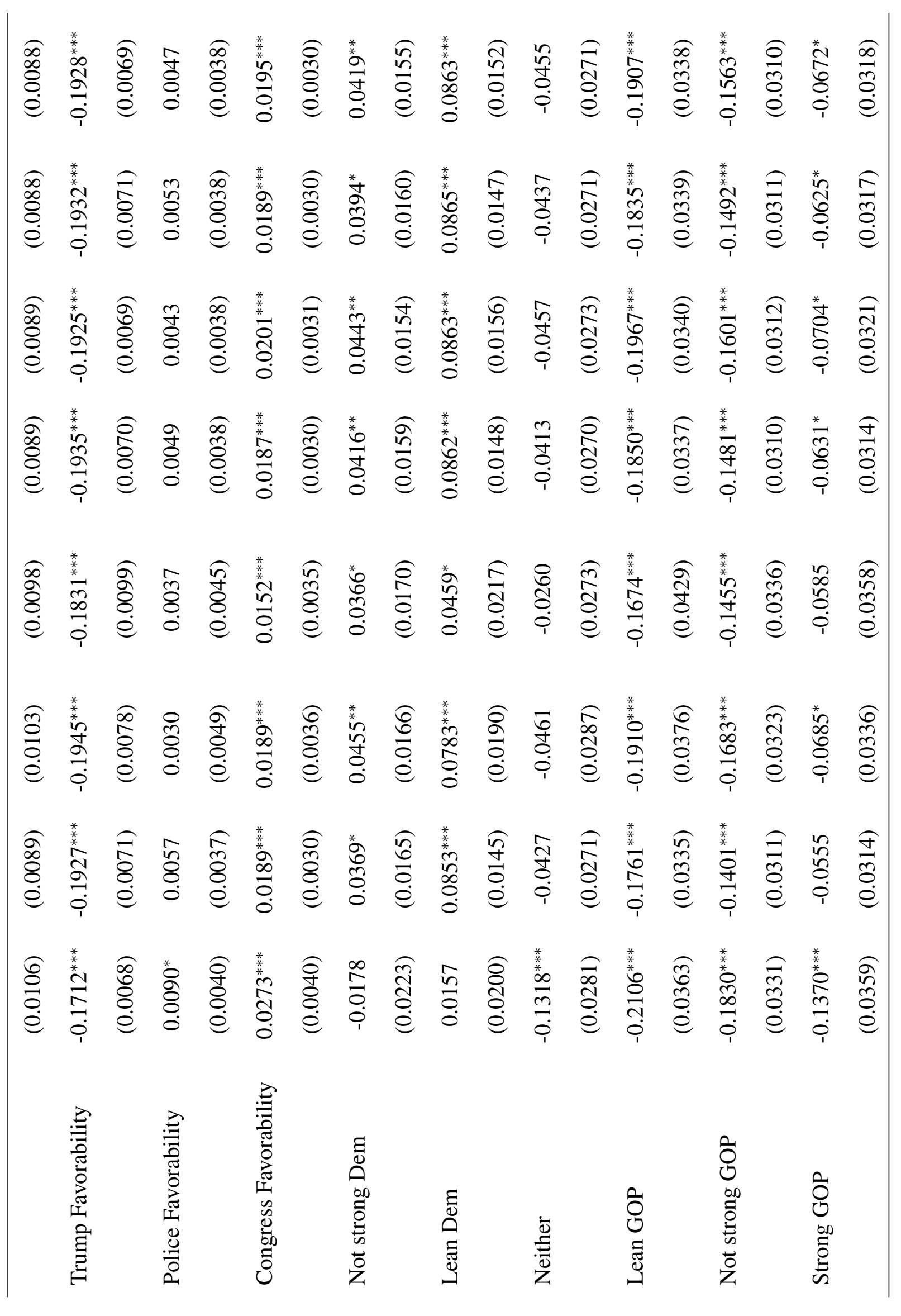




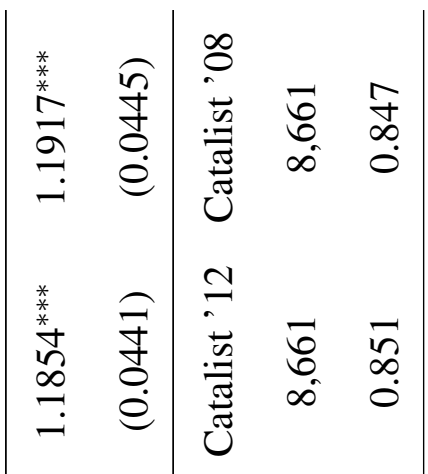

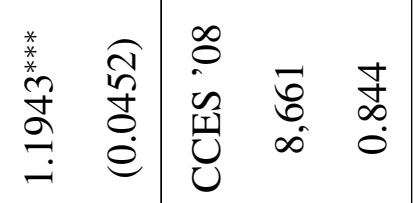

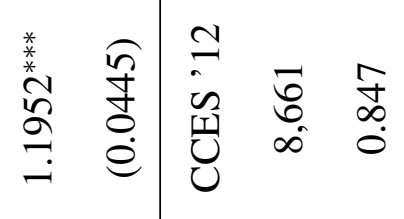

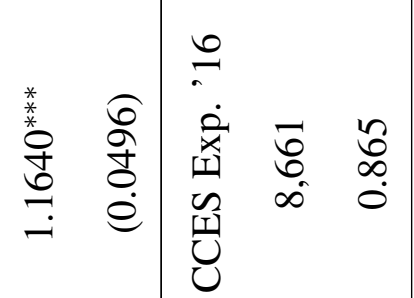

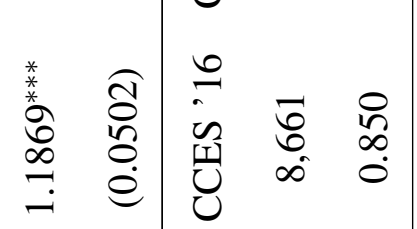

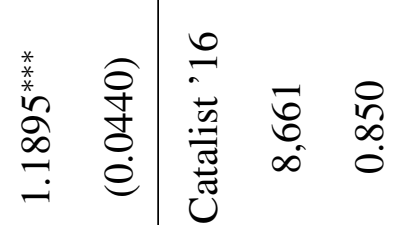

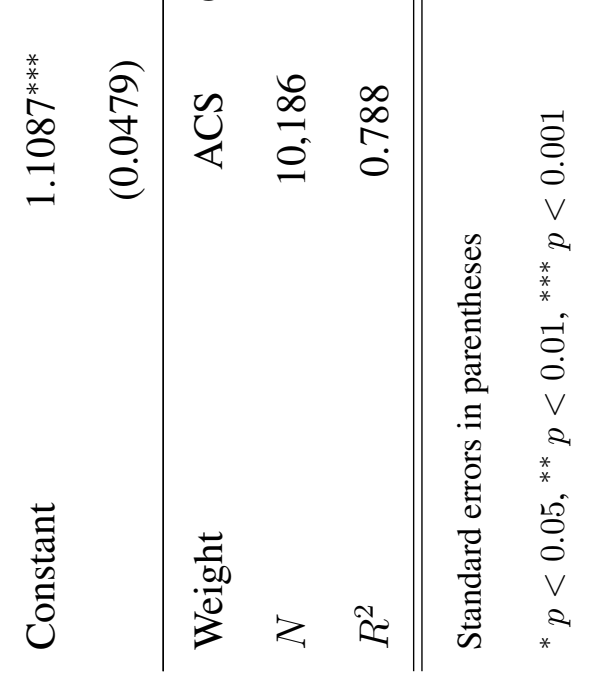




\section{B Question Wordings}

The survey questions had the following wordings and response options:

1. If the 2020 election for President of the United States were held today between Republican Donald Trump and Democrat [DEM CANDIDATE], who would you vote for? [Round 1 Responses: Republican Donald Trump, Democrat [DEM CANDIDATE], Undecided, A third party candidate]. [Round 2 Responses: Republican Donald Trump, Democrat [DEM CANDIDATE], Undecided, A third party candidate, I would not vote].

2. [If Undecided, third party, or would not vote] If you had to choose, would you lean towards Republican Donald Trump or Democrat [DEM CANDIDATE]? [Round 1 Responses: Lean towards Republican Donald Trump, Lean towards Democrat [DEM CANDIDATE], Completely undecided] [Round 2 Responses: Lean towards voting for Republican Donald Trump, Lean towards voting for Democrat [DEM CANDIDATE], Completely undecided, I definitely would not vote] 